\title{
Variance Premium, Downside Risk and Expected Stock Returns
}

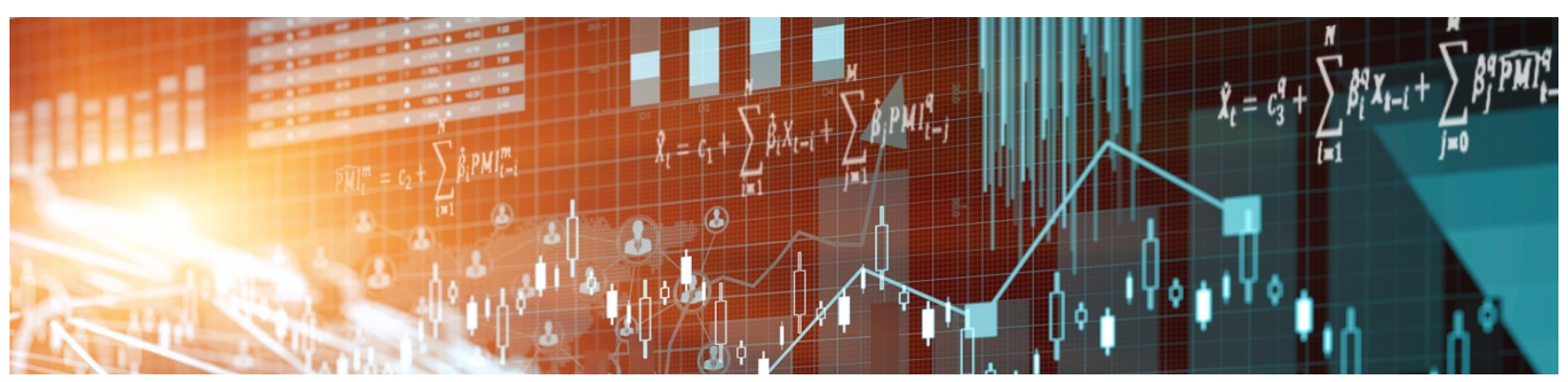

by Bruno Feunou, Ricardo Lopez Aliouchkin, Roméo Tédongap and Lai Xi 
Bank of Canada Staff Working Paper 2017-58

December 2017

\title{
Variance Premium, Downside Risk and Expected Stock Returns
}

\author{
by \\ Bruno Feunou, ${ }^{1}$ Ricardo Lopez Aliouchkin, Roméo Tédongap ${ }^{2}$ \\ and Lai Xi \\ 1 Financial Markets Department \\ Bank of Canada \\ Ottawa, Ontario, Canada K1A 0G9 \\ feun@bankofcanada.ca \\ 2 Department of Finance \\ ESSEC Business School \\ 95021 Cergy-Pontoise Cedex, France
}




\section{Acknowledgements}

We thank Bo-Young Chang, Jonathan Witmer, participants of the 2017 OptionMetrics Research Conference and ESSEC Business School's 4th Empirical Finance Workshop, as well as seminar participants at the University of Reading. Feunou gratefully acknowledges financial support from the IFSID. Lopez Aliouchkin and Tédongap acknowledge the research grant from the Thule Foundation's Skandia research programs on "Long-Term Savings." 


\begin{abstract}
We decompose total variance into its bad and good components and measure the premia associated with their fluctuations using stock and option data from a large cross-section of firms. The total variance risk premium (VRP) represents the premium paid to insure against fluctuations in bad variance (called bad VRP), net of the premium received to compensate for fluctuations in good variance (called good VRP). Bad VRP provides a direct assessment of the degree to which asset downside risk may become extreme, while good VRP proxies for the degree to which asset upside potential may shrink. We find that bad VRP is important economically; in the cross-section, a one-standard-deviation increase is associated with an increase of up to $13 \%$ in annualized expected excess returns. Simultaneously going long on stocks with high bad VRP and short on stocks with low bad VRP yields an annualized risk-adjusted expected excess return of $18 \%$. This result remains significant in double-sort strategies and cross-sectional regressions controlling for a host of firm characteristics and exposures to regular and downside risk factors.
\end{abstract}

Bank topics: Asset pricing; Financial markets

JEL code: G12

\title{
Résumé
}

Nous décomposons la variance totale en ses éléments positifs et négatifs et mesurons les primes associées à leurs fluctuations à partir de données sur les actions et les options, données tirées d'un vaste échantillon représentatif d'entreprises. La prime liée au risque de la variance (PRV) totale représente la prime à payer pour s'assurer contre les fluctuations d'une variance négative (appelée mauvaise PRV), après déduction de la prime reçue pour compenser les fluctuations de la variance positive (appelée bonne PRV). La mauvaise PRV fournit une évaluation directe du degré d'exacerbation du risque à la baisse pesant sur les actifs, alors que la bonne PRV donne une indication du degré de réduction de la hausse potentielle des prix d'actifs. Nous constatons que la mauvaise PRV revêt une importance économique; dans l'échantillon représentatif d'entreprises, à une augmentation d'un écart-type correspond une augmentation de l'excédent de rendement attendu pouvant aller jusqu'à 13 \% (en taux annualisé). Prendre une position longue sur des titres assortis d'une mauvaise PRV élevée, en concomitance avec une position courte sur des titres assortis d'une mauvaise PRV faible, procure un excédent de rendement attendu (en taux annualisé, ajusté en fonction des risques) de $18 \%$. Ces résultats demeurent significatifs dans les stratégies dichotomiques et les régressions transversales tenant compte d'une série de caractéristiques des entreprises et d'expositions à des risques habituels ainsi qu'à des risques à la baisse.

Sujets : Évaluation des actifs; Marchés financiers

Codes JEL : G12 


\section{Non-Technical Summary}

The proper assessment of risk is of paramount importance to investment decisions, given the basic trade-off between risk and reward. The variance risk premium (VRP) is a measure of risk compensation used by investors and policy makers to gauge investor sentiment about uncertainty. The VRP is the difference between the forward-looking market variance implied by option prices and the actual variance realized over time.

Yet, while the VRP can be a valuable tool to appraise the uncertainty around future variations in stock returns (including around extreme events), this measure does not take into consideration one important point: not all uncertainties are bad. Intuitively, investors like good uncertainty (as it increases the potential of substantial gains) but dislike bad uncertainty (as it increases the likelihood of severe losses). Thus we believe that it is not enough to merely look at the VRP as a whole. To improve our understanding of the distribution of future stock returns, we need to further dissect this information and scrutinize both the good and the bad pieces. Indeed, failure to do so implies mixing two opposing views of the market.

Thus, building on this intuition, we dissect the VRP of over 5000 firms into its bad and good components. We find that bad VRP is important economically; in the cross-section, a onestandard-deviation increase is associated with an increase of up to $13 \%$ in annualized expected excess returns. Simultaneously, going long stocks with high bad VRP and short stocks with low bad VRP yields an annualized risk-adjusted expected excess return of $18 \%$. This result remains significant in double-sort strategies and cross-sectional regressions controlling for a host of firm characteristics and exposures to regular and downside risk factors.

Likewise, we also find that good variance risk premium has a negative relationship with expected stock returns, albeit it is not statistically significant. Since the bad and good components of the variance risk premium have opposite effects in the cross-section, this may explain why we find weaker evidence on the relationship between total variance risk premiums and expected stock returns.

This knowledge would greatly benefit researchers in the fields of finance and financial econometrics. It is also a procedure that anyone monitoring the financial system can implement to more accurately predict equity's risk premium. 


\section{Introduction}

Today's financial environment is marked by a rapid development of sophisticated quantitative tools and models used by investors to improve asset return forecasts. These forecasts are obtained more or less precisely depending on the available information set. In theory, investors care not only about the expected returns, but also about the degree of imprecision affecting these return forecasts as measured by the total variance of returns. As the investors' information set changes through time, the total variance of returns also fluctuates, suggesting that the magnitude of the forecast error changes through time. Furthermore, as investors would prefer to underestimate returns (positive surprise) rather than overestimate them (negative surprise), they prefer a high degree of imprecision when it results in a positive forecast error (good variance scenario) and they dislike it when it results in a negative forecast error (bad variance scenario).

Motivated by the unequal perception of variance scenarios by investors, we decompose the total variance of an asset into a bad and a good component. Formally, the bad variance measures the variance of returns conditional on realizations below expectations. To the contrary, good variance measures the variance of returns conditional on realizations exceeding expectations. While expected returns are a natural reference point for disentangling bad and good variances, other thresholds may be considered depending on investors' objective and attitude toward risk, such as zero, the risk-free rate, a certainty equivalent, or any quantile of the return distribution. The asymmetric treatment of bad and good variances has a long standing in the academic literature (see for example Roy, 1952 and Markowitz, 1959) and has motivated the development of theories of rational behavior under uncertainty that imply priced downside risks in the capital market equilibrium (see for example Bawa and Lindenberg, 1977, Kahneman and Tversky, 1979, Quiggin, 1982, Gul, 1991, and Routledge and Zin, 2010).

Just as total variance fluctuates through time, the bad and good components also do. The finance literature has traditionally focused on characterizing the compensation an investor demands for bearing fluctuations in equity returns. However, as already discussed, investors are also exposed to variance fluctuations. If an investor dislikes (likes) a high level of variance, she could enter a corresponding variance swap contract as variance buyer and would be willing to pay a fixed rate that is higher (lower) than her expected variance. For a variance the investor dislikes, the fixed rate 
minus the expected variance is positive on average and defines the so-called variance risk premium, which is the premium the investor would be willing to pay in order to hedge market situations with sharp increases in variance; thus the investor would typically pay the variance risk premium to be able to enjoy the large positive payoff of the variance swap in times of strong variance realizations. To the contrary, for a variance the investor likes, the expected variance minus the fixed rate is positive on average and defines the variance risk premium, which is the premium the investor would be willing to receive in order to undergo market situations with sharp decreases in variance. In this case the investor would typically require the variance risk premium to be able to endure the large negative payoff of the variance swap in times of weak variance realizations.

Since investors dislike bad variance and prefer good variance for reasonable thresholds, the bad variance risk premium is the premium an investor would be willing to pay to insure against increases in bad variance, while the good variance risk premium is the premium she would be willing to receive as compensation for decreases in good variance. By definition, the total variance risk premium is the bad variance risk premium minus the good variance risk premium; thus the total variance risk premium can be interpreted as the premium paid for insurance against fluctuations in bad variance net of the premium earned to compensate for fluctuations in good variance. Thus, our decomposition of the total variance risk premium into a bad and good component provides a cost/benefit analysis of investing in the variance swap. This is because the total variance risk premium finally measures by how much the cost of insuring against fluctuations in bad variance exceeds the benefit for being exposed to fluctuations in good variance.

In this paper, we argue that the premium an investor demands for holding a risky asset must reflect the bad variance risk premium. An asset that has a large bad variance risk premium is an unattractive asset because it would be expensive for the investor to insure against undesirable fluctuations of the asset bad variance. Investors who are sensitive to fluctuations in bad variance thus require a high premium for holding assets with high bad variance risk premium. Thus, in an economy where investors care about fluctuations in bad variance, assets with larger bad variance risk premium will have higher returns on average. We empirically explore our cross-sectional prediction using US equity stock and option data from January 1996 to December 2015. Whether variance is the total, the bad or the good, stock data are used to measure realized variance as in 
Barndorff-Nielsen et al. (2010) and to estimate the (real-world) expected variance using a variant of the Heterogenous Autoregressive model of Realized Volatility (HAR-RV) model of Corsi (2009). Likewise, option data are used as in Kilic and Shaliastovich (forthcoming), based on Bakshi et al. (2003) and Bakshi and Madan (2000), to measure the risk-neutral expected variance, which also represents the no-arbitrage fixed rate paid by the variance buyer in the variance swap contract. Our measure of the total, bad and good variance risk premium is the difference between the corresponding risk-neutral and real-world expected realized variance.

Our main cross-sectional tests use portfolio sorts based on each firm's bad variance risk premium, eventually controlling for firm characteristics and other measures of firm riskiness, including exposures to frequently investigated market factors. Across firms, we see a wide dispersion in bad variance risk premium, which generates cross-sectional variation in risk premia. Our main finding provides strong evidence that individual firm bad variance risk premium is positively related to expected excess returns in the cross-section, and this relationship is highly statistically significant. Specifically, simultaneously going long a portfolio of firms with high bad variance risk premium and short a portfolio of firms with low bad variance risk premium yields an annualized expected excess return of $17.6 \%$, risk-adjusted using the five-factor model of Fama and French (2015). Likewise, we also find that the good variance risk premium has a positive relationship with expected stock returns, albeit it is less statistically significant. Since the bad and good components of the variance risk premium have similar effects in the cross-section, this may explain why we find weaker evidence on the relationship between total variance risk premium and expected stock returns. Crucially, our results point to the fact that analyzing the relationship between expected stock returns and the variance risk premium imperatively requires the decomposition of the variance risk premium into its bad and good components. We use Fama and MacBeth (1973) cross-sectional regressions to estimate the price of risk associated with the bad variance risk premium. The bad variance risk premium provides significant explanatory power on the variation of expected stock returns beyond traditional asset pricing factor risks, firm characteristics, as well as concurrent measures such as signed jump variation considered by Bollerslev et al. (2017). Our estimates suggest that the bad variance risk premium is economically important with a one-standard-deviation increase associated with a rise in annualized expected excess returns between $6.7 \%$ and $12.7 \%$ in the cross-section. 
This paper builds directly on the developing literature that investigates the connections between expected returns and the variance risk premium. In the literature, these connections have been examined mainly for the aggregate stock market through time-series predictability studies where the variance risk premium appears to be a strong short-term predictor of equity returns, whereas the dividend yield appears to be a long-term predictor. Bollerslev et al. (2009) show that the US stock market variance risk premium can predict excess returns up to a quarterly horizon. Bollerslev et al. (2014) extend the analysis to international stock markets and find similar predictability patterns for the variance risk premium in a range of countries. Carr and $\mathrm{Wu}$ (2009) provide a time-series analysis of the individual variance risk premium for 35 firms, but they do not explore any crosssectional relationship with expected stock returns. To the contrary, we analyze the individual variance risk premium of a much larger sample of firms consisting of 5150 firms, and we explore the cross-sectional relationship with expected stock returns.

More recent time-series predictability studies corroborate the benefit of separating the bad and good component of variance risk premium. Kilic and Shaliastovich (forthcoming) document that these components jointly predict excess returns well at longer horizons where the total variance risk premium fails. Feunou et al. (forthcoming) offer an alternative characterization of the bad and good component and find that the bad is the main component of the market variance risk premium. Furthermore, they show that the bad variance risk premium drives the documented market excess return predictability of the market variance risk premium.

Cross-sectional studies analyzing the links between expected returns and the variance risk premium are rare and almost nonexistent. One exception is Han and Zhou (2011), and there are several differences between our studies. First, their focus is on individual firm total variance risk premium, while we extend the analysis to its bad and good components. To the best of our knowledge, this is the first paper providing an in-depth cross-sectional analysis of the individual firm variance risk premium at a disaggregated level. Second, we have a different and longer sample period, and due to the growth of the options market during recent years, our sample contains significantly more firms. While we focus on explaining cross-sectional variation in expected returns by the heterogeneity in variance risk premium across stocks, another strand of the literature analyzes the determinants of the cross-sectional variation of variance risk premium instead. For example, González-Urteaga 
and Rubio (2016) show that differences in variance risk premium across stocks reflect differences in exposures of stock variance to key systematic factors such as the market variance risk premium and, especially, the default premium.

Our paper also relates to the parallel literature documenting the importance of analyzing the bad and good components of volatility. Feunou et al. (2013) and Bekaert et al. (2015) extend the GARCH framework of Bollerslev (1986) to model these two components of market volatility and analyze their implications on market returns. Patton and Sheppard (2015) use realized semivariance measures introduced by Barndorff-Nielsen et al. (2010) to predict future market volatility and find that bad volatility is a better predictor than good volatility. In addition, they find a similar conclusion for 105 individual firms. Bollerslev et al. (2017) provide a cross-sectional analysis of the relationship between expected returns and signed jump variation. They find that signed jump variation, which they define as the difference between good and bad realized variance, is significantly related to expected stock returns. We notice that the relative signed jump variation considered by Bollerslev et al. (2017) is a measure of skewness, as demonstrated by Feunou et al. (2016). In that sense, Bollerslev et al. (2017) are analyzing implications of individual firms' skewness for the cross-section of expected stock returns. In contrast, we focus on bad and good variance risk premium, which are the respective cost and benefit associated with fluctuations in bad and good realized variances. Even when controlling for realized semi-variances, bad variance risk premium has a significantly positive relationship with expected stock returns.

Our paper finally relates to the growing literature that examines the cross-sectional implications of downside risk (see for example articles by Ang et al., 2006a, Lettau et al., 2014 and Farago and Tédongap, forthcoming), but differs from the literature in that our measure for downside risk does not represent a firm's exposure or beta relative to given market-wide factors, but instead corresponds to the firm's specific cost to insure against undesirable fluctuations of its stock uncertainty when perceived as bad by investors. Empirical tests and evidence in Daniel and Titman $(1997,2012)$ support our approach of measuring downside risk through a firm's specific characteristic rather than factor exposure. Nevertheless, we analyze double-sort strategies as well as Fama-MacBeth regressions controlling for multivariate exposures to the five cross-sectional pricing factors implied by the generalized disappointment aversion (GDA) asset pricing model under fluctuating macroeconomic 
uncertainty as derived by Farago and Tédongap (forthcoming). Our results suggest that variation in expected stock returns that are explained by GDA factor exposures are fully accounted for by cross-sectional heterogeneity in firm bad variance risk premium.

The rest of the paper is organized as follows. Section 2 introduces the methodology used to estimate individual firms' variance risk premium. Section 3 introduces the data and presents descriptive statistics of all measures. In Section 4, we investigate the cross-sectional relationship between variance risk premium and expected stock returns. Section 5 concludes. A supplemental appendix contains additional details and results that are omitted from the main text for brevity.

\section{Overview of Theory and Methodology}

\subsection{Variance Risk Premium: Decomposition and Interpretation}

For a given stock, we consider its realized variance aggregated over a monthly period based on high-frequency returns, which we define by

$$
R V_{t-1, t}=\sum_{j=1}^{1 / \delta} r_{t-1+j \delta}^{2}
$$

where $1 / \delta$ is the number of high-frequency returns assumed for the monthly period, i.e., $\delta=1 / 21$ for daily returns, $r_{t-1+j \delta}$ denotes the $j$ th high-frequency return of the monthly period starting at date $t-1$ and ending at date $t$, and $R V_{t-1, t}$ is the monthly total realized variance.

Denoting by $\mathbb{I}(\cdot)$ the indicator function that takes the value 1 if the condition is met and 0 otherwise, we follow Barndorff-Nielsen et al. (2010) and split the total realized variance into two components, which they refer to as realized semi-variances, as follows:

$$
\begin{aligned}
& R V_{t-1, t}=R V_{t-1, t}^{b}+R V_{t-1, t}^{g} \text { where } \\
& R V_{t-1, t}^{b}=\sum_{j=1}^{1 / \delta} r_{t-1+j \delta}^{2} \mathbb{I}\left(r_{t-1+j \delta}<0\right) \text { and } R V_{t-1, t}^{g}=\sum_{j=1}^{1 / \delta} r_{t-1+j \delta}^{2} \mathbb{I}\left(r_{t-1+j \delta} \geq 0\right),
\end{aligned}
$$

where $R V_{t-1, t}^{b}$ captures the part of the variance due to negative returns only, corresponding to our definition for bad variance, while $R V_{t-1, t}^{g}$ captures the variation due to positive returns only, corresponding to our definition for good variance (see Patton and Sheppard, 2015, Kilic and Shalias- 
tovich, forthcoming, and Bollerslev et al., 2017 for the same analogy).

Since risk-averse investors are averse to increases in the total variance of a stock, with a long position in the corresponding variance swap, they will enjoy a large positive payoff if the stock variance realizes strongly. For the privilege of savouring this payoff in hard times when investor marginal utility is high, risk-averse investors would pay a fixed swap rate that is higher than their (real-world) expectation of the stock realized variance if variance covaries positively with the investor's marginal utility, so that the swap rate minus the expected variance would be positive, then representing the variance risk premium. Since a stock variance swap has zero net market value at inception, the no-arbitrage condition dictates that the swap rate is equal to the riskneutral expected value of the realized variance. We formally define the total variance risk premium of a stock as follows:

$$
\begin{aligned}
V R P_{t} & \equiv \mathbb{E}_{t}^{\mathbb{Q}}\left[R V_{t, t+1}\right]-\mathbb{E}_{t}\left[R V_{t, t+1}\right] \\
& =\operatorname{Cov}_{t}\left(Q_{t, t+1}, R V_{t, t+1}\right),
\end{aligned}
$$

where $\mathbb{E}_{t}[\cdot]$ denotes the time- $t$ real-world conditional expectation operator, $\mathbb{E}_{t}^{\mathbb{Q}}[\cdot]$ denotes the time$t$ conditional expectation operator under some risk-neutral measure $\mathbb{Q}$ associated with the state price density $Q_{t, t+1}$ used to price assets between time $t$ and time $t+1$, and $\operatorname{Cov}_{t}(\cdot, \cdot)$ is the time- $t$ real-world conditional covariance operator. The variance risk premium will be negative instead if stock variance covaries negatively with the investor marginal utility, the long side of the variance swap requesting a premium to compensate for the large negative payoff suffered in hard times.

The finance literature has long evidenced that bad and good variances are not equally undesirable by risk-averse investors. For example, Markowitz (1959) advocates the use of the downside semi-variance (namely, bad variance) as the measure of stock risk instead of the total variance, since the total variance also accounts for the upside semi-variance (namely, good variance) which measures not the risk but the potential of a stock. More recently, Feunou et al. (2013), Bekaert et al. (2015) and Segal et al. (2015) find that expected excess returns on stocks are positively related to bad variance while they are negatively related to good variance. This suggests that, on the one hand, risk-averse investors are averse to increases in bad variance. If longing the swap of bad variance, they would be willing to pay a swap rate higher than their expectation for bad variance if 
variance tends to increase with investor marginal utility. They would thus be paying an insurance premium to enjoy the large positive payoff of the swap when investors are worse off and variance realizes strongly. On the other hand, to the contrary, risk-averse investors desire increases in good variance. If holding a long position in the swap of good variance, they would be willing to pay a swap rate lower than their expectation for good variance if variance covaries negatively with investor marginal utility, thus receiving a premium to endure the large negative payoff of the swap in case of a weak realization of variance when investors are worse off.

Consistent with these views, we define the bad and good variance risk premiums as follows:

$$
\begin{array}{rlrl}
V R P_{t}^{b} & \equiv \mathbb{E}_{t}^{\mathbb{Q}}\left[R V_{t, t+1}^{b}\right]-\mathbb{E}_{t}\left[R V_{t, t+1}^{b}\right] \quad \text { and } V R P_{t}^{g} & \equiv \mathbb{E}_{t}\left[R V_{t, t+1}^{g}\right]-\mathbb{E}_{t}^{\mathbb{Q}}\left[R V_{t, t+1}^{g}\right] \\
& =\operatorname{Cov}_{t}\left(Q_{t, t+1}, R V_{t, t+1}^{b}\right) & & =\operatorname{Cov}_{t}\left(-Q_{t, t+1}, R V_{t, t+1}^{g}\right)
\end{array}
$$

so that they are positive if variance tends to move adversely in hard times when investors are worse off and their marginal utility is high. In consequence, using the decomposition of total variance in Equation (2), the total variance risk premium in Equation (3) may be written

$$
V R P_{t}=V R P_{t}^{b}-V R P_{t}^{g}
$$

Equation (5) shows that the total variance risk premium represents the net cost of insuring fluctuations in bad variance, that is the premium paid for insurance against fluctuations in bad variance net of the premium earned to compensate for fluctuations in good variance.

Another key measure for assessing the riskiness of a stock and also related to the realized semi-variances is the realized relative semi-variance introduced by Feunou et al. $(2013,2016)$ as a measure of asymmetry, defined as the difference between the upside and the downside semivariances, and referred to as signed jump variation by Patton and Sheppard (2015) and Bollerslev et al. (2017). The signed jump variation is defined by

$$
R J_{t-1, t} \equiv R V_{t-1, t}^{g}-R V_{t-1, t}^{b}
$$

and the risk premium on the signed jump variation, which we subsequently refer to simply as the 
signed jump risk premium (JRP), may easily be obtained as

$$
\begin{aligned}
J R P_{t} & \equiv \mathbb{E}_{t}\left[R J_{t, t+1}\right]-\mathbb{E}_{t}^{\mathbb{Q}}\left[R J_{t, t+1}\right] \\
& =V R P_{t}^{b}+V R P_{t}^{g} .
\end{aligned}
$$

Variations of the long-run risks asset pricing model pioneered by Bansal and Yaron (2004) that allow for stochastic volatility of volatility are used to study the variance risk premium of the aggregate stock market by Bollerslev et al. (2009), Drechsler and Yaron (2011), and Bonomo et al. (2015). If, as most economists would probably agree, the average investor is sufficiently risk averse (typically more than an investor with logarithmic utility) and displays preference for early resolution of uncertainty, then these models predict that the variance risk premium is positive. In a long-run risk model, Held et al. (2016) compute the two components of the total variance risk premium (which they refer to as premia on second semi-moments) of the aggregate stock market and confirm that the bad and good variance risk premiums as defined in Equation (4) are positive. Altogether the theory implies that, for an asset for which variance moves together with investor marginal utility, the cost of insuring against fluctuations in bad variance exceeds the benefit for being exposed to fluctuations in good variance, and the variance risk premium measures by how much.

\subsection{Measuring Variance Risk Premium}

Measuring variance risk premium amounts to estimating the real-world and risk-neutral conditional expectations of realized variance and taking their difference. In theory these expectations are conditional on the same information set, and therein lies precisely the main empirical challenge. While theoretical asset pricing models, including all versions of the long-run risks model mentioned above, imply that both real-world and risk-neutral conditional expectations of realized variance depend on the same processes governing the state of the economy, in the empirical literature this theoretical implication is hard to satisfy. We argue that this mismatch of conditioning information in empirical measurement of the two conditional expectations may explain some differences between theory and empirics, for example, the fact that the empirical estimates of the variance risk premium as defined is Equation (3) may display negative values for the aggregate stock market while the 
theory predicts that it is positive (see for example plots of the aggregate stock market variance risk premium in Bollerslev et al., 2009).

In practice, the risk-neutral conditional expectation of realized variance is estimated by exploiting the price of the quadratic payoff measured directly from a cross-section of option prices using the results in Bakshi et al. (2003). The authors provide a model-free formula linking the moments of the risk-neutral distribution of stock returns to an explicit portfolio of options. Their results are based on the basic notion, first presented formally in Bakshi and Madan (2000), that any payoff can be spanned by a set of options with different strikes and a given maturity. Thus, all estimates of the risk-neutral expectation of variance extracted using this method will be for a given maturity.

Following Bakshi et al. (2003), we define $V_{t}(\tau)$ as the time- $t$ price of the $\tau$-maturity (days-tomaturity) quadratic contract on the underlying stock. Bakshi et al. (2003) show that the price of this quadratic contract can be recovered from the market prices of out-of-the-money call and put options as follows:

$$
V_{t}(\tau)=\int_{S_{t}}^{\infty} \frac{1-\ln \left(K / S_{t}\right)}{K^{2} / 2} C_{t}(\tau ; K) d K+\int_{0}^{S_{t}} \frac{1+\ln \left(S_{t} / K\right)}{K^{2} / 2} P_{t}(\tau ; K) d K
$$

We see that the price of this contract is based on an explicit positioning on a set of options $C_{t}(\tau ; K)$ and $P_{t}(\tau ; K)$, where the former is the time- $t$ price of a call option on the underlying stock with maturity $\tau$ and strike $K$, while the latter is the price of a put option with similar characteristics. We define the risk-neutral expectation of the total variance of the underlying stock as

$$
\mathbb{E}_{t}^{\mathbb{Q}}\left[R V_{t, t+1}\right] \equiv e^{r \tau} V_{t}(\tau)
$$

where $r$ is the appropriate continuously compounded interest rate.

In theory, to compute $V_{t}(\tau)$ requires a continuum of strike prices while in practice we only observe a discrete and finite set of strike prices. Following the literature (e.g., Jiang and Tian, 2005), to obtain a continuum of strike prices we use cubic splines to interpolate inside the available moneyness range, and extrapolate using the last known boundary value to fill in a total of 1001 grid points of implied volatilities in the moneyness range from $1 / 3$ to 3 . We then calculate option prices from the interpolated volatilities using the known interest rate for a given maturity using 
the Black-Scholes (Black and Scholes, 1973) formula. Following the extant literature (e.g., Conrad et al., 2013), for the interpolation and extrapolation step we require that there are at least four observed option prices. ${ }^{1}$ We discretize the integrals in Equation (8) and use the option prices obtained from the implied volatilities to compute the risk-neutral expected variance. In the end, this process yields a daily time series of risk-neutral expected variance for each firm in our sample.

Kilic and Shaliastovich (forthcoming) and Feunou et al. (forthcoming) examine the bad and good components of the S\&P 500 variance risk premium from the perspective of aggregate stock market time-series predictability. Instead we compute the bad and good components of the stock variance risk premium for all firms with available data and focus on cross-sectional predictability. We follow Kilic and Shaliastovich (forthcoming) and define the risk-neutral expectations of the bad and good realized variances of the underlying stock as follows:

$$
\mathbb{E}_{t}^{\mathbb{Q}}\left[R V_{t, t+1}^{b}\right] \equiv e^{r \tau} V_{t}^{b}(\tau) \text { and } \mathbb{E}_{t}^{\mathbb{Q}}\left[R V_{t, t+1}^{g}\right] \equiv e^{r \tau} V_{t}^{g}(\tau)
$$

where

$$
V_{t}^{b}(\tau)=\int_{0}^{S_{t}} \frac{1+\ln \left(S_{t} / K\right)}{K^{2} / 2} P_{t}(\tau ; K) d K \text { and } V_{t}^{g}(\tau)=\int_{S_{t}}^{\infty} \frac{1-\ln \left(K / S_{t}\right)}{K^{2} / 2} C_{t}(\tau ; K) d K
$$

Intuitively, as $V_{t}^{b}$ is estimated solely from put options it represents the potential of a payoff from downward movements in the underlying security. On the other hand, $V_{t}^{g}$ is estimated solely from out-of-the-money call options and thus it represents the potential of a payoff from upward movements in the underlying stock.

We estimate the real-world conditional expectation of good and bad realized variances of each stock in our sample using a variant of the HAR-RV model of Corsi (2009). While the original model is used to forecast daily realized variance using past day, past week, and past month realized variances, our variant is used to forecast the monthly realized variance using past month, past

\footnotetext{
${ }^{1}$ Due to this requirement, we cannot compute estimates for the risk-neutral expectation of variance for some stocks for each day in the sample. However, relaxing this requirement would be inconsistent with the existing literature and may lead to estimates that are not robust.
} 
five-month, and past two-year realized variances as follows:

$$
\begin{aligned}
& \mathbb{E}_{t}\left[R V_{t, t+1}^{b}\right]=\omega^{b}+\beta_{1}^{b} R V_{t-1, t}^{b}+\beta_{5}^{b} R V_{t-5, t}^{b}+\beta_{24}^{b} R V_{t-24, t}^{b}+\beta_{1}^{b \prime} R V_{t-1, t}^{g}+\beta_{5}^{b \prime} R V_{t-5, t}^{g}+\beta_{24}^{b \prime} R V_{t-24, t}^{g} \\
& \mathbb{E}_{t}\left[R V_{t, t+1}^{g}\right]=\omega^{g}+\beta_{1}^{g \prime} R V_{t-1, t}^{b}+\beta_{5}^{g \prime} R V_{t-5, t}^{b}+\beta_{24}^{g \prime} R V_{t-24, t}^{b}+\beta_{1}^{g} R V_{t-1, t}^{g}+\beta_{5}^{g} R V_{t-5, t}^{g}+\beta_{24}^{g} R V_{t-24, t}^{g},
\end{aligned}
$$

where the bad and good components are separated in the right-hand side of the regression in order to account for their asymmetric effects in volatility forecasting, as highlighted in Patton and Sheppard (2015). Their findings provide strong evidence that decomposing realized variance into its bad and good components significantly improves the explanatory power of the HAR-RV model. The real-world forecast of total realized variance is simply the sum of the forecasts of its two components displayed in Equation (12).

\subsection{The Cross-Section of Variance Risk Premium and Expected Stock Returns}

Our study examines the cross-sectional relationship between individual stock variance risk premium and expected excess returns. Our theoretical motivation builds on the intuition that, since investors dislike assets with extremely high downside risk, they would require higher expected returns for holding those assets. The asset downside risk is summarized by its bad variance, and fluctuations in the bad variance are undesirable because they may result in extremely high downside risk. The bad variance risk premium paid by investors to insure against extremely high downside risk is thus a natural proxy for the degree to which downside risk may become extreme, as an insurance premium increases with the size of the damage. We must then observe that assets with high bad variance risk premium command higher expected excess returns in the cross-section.

A similar reasoning applies to the good variance risk premium. Investors dislike assets with excessively low upside potential and would require a higher expected return for holding them. The asset upside potential is summarized by its good variance, and fluctuations in the good variance are undesirable because they may result in excessively low upside potential. The good variance risk premium requested by investors to compensate for excessively low upside potential is thus a natural proxy for the degree to which upside potential may shrink, as a compensation increases with the size of the penalty. We must then observe that assets with high good variance risk premium 
command higher expected excess returns in the cross-section.

Given a factor-based specification of the state price density $Q_{t, t+1}$ common in the asset pricing literature, Equation (3) would relate the stock variance risk premium to the covariance between the stock variance and the systematic factors. It then can formally be tested to determine whether cross-sectional differences in variance risk premium across stocks are explained by cross-sectional differences in variance betas on the systematic factors. A recent article by González-Urteaga and Rubio (2016) addresses this issue by using selective groups of systematic factors including market return together with squared market return, and market variance risk premium together with the default premium calculated as the difference between Moody's yield on Baa corporate bonds and the ten-year government bond yield. Their findings suggest that market variance risk premium and the default premium are key factors explaining average variance risk premium across stock portfolios.

Notice from the covariance representation in Equation (4) that bad and good variance risk premia are also related respectively to exposures of bad and good variances to factors governing the marginal utility of the average investor equivalent to the state price density. In that sense, if expected returns are related to bad and good variance risk premia in the cross-section, then they should also be related to these factor exposures. By examining the relationships between expected returns and individual stock-specific characteristics instead of factor exposures, we follow the suggestion based on theoretical and empirical evidence in Daniel and Titman (1997, 2012) which favor such a methodological approach.

Finally, to verify the robustness of our findings, we control for various cross-sectional effects put forward in the empirical literature. These include idiosyncratic volatility, which is measured as in Ang et al. (2006b) relative to the Fama-French three-factor model, illiquidity measured as in Amihud (2002), risk-neutral skewness computed following Bakshi et al. (2003) and examined by Conrad et al. (2013), signed jump variation examined by Bollerslev et al. (2017), and exposures to some market-wide factors such as market risk-neutral skewness examined by Chang et al. (2013), market variance risk premium (Han and Zhou, 2011, and González-Urteaga and Rubio, 2016), and downside risk factors motivated by the behavioral theory of disappointment aversion of Gul (1991) and examined by Farago and Tédongap (forthcoming). 


\section{Data and Descriptive Statistics}

\subsection{Firm Characteristics and Return Data}

The data for individual daily equity and S\&P500 returns is obtained from the Center for Research in Security Prices (CRSP) database. The data on the daily market excess returns, size, value, and momentum factors is obtained from the online data library of Kenneth R. French. To compute daily equity excess returns, we subtract the one-month Treasury bill rate. The data for the onemonth Treasury bill rate is also obtained from the online data library of Kenneth R. French. ${ }^{2}$ The sample period for the empirical analysis ranges between January 1996 to December 2015, but in order to compute the realized variance we require two years of daily returns prior to the start of our sample. Thus, the individual return data ranges from January 1994 to December 2015. The data on market capitalization and book value is obtained from CRSP and Compustat, respectively. We compute the prior 12-month return as the stock's cumulative excess returns during the 12-month period from $t-13$ to $t-2$ in order to avoid spurious effects. Size is computed as the log of the market capitalization, while the book-to-market variable is computed as the book value divided by the market capitalization. ${ }^{3}$

\subsection{Option Data}

For the estimation of the risk-neutral expected variance, we rely on individual equity option prices obtained from the IvyDB OptionMetrics database for the period of January 1996 to December 2015. Consistent with the literature (e.g., Carr and Wu, 2009) we exclude options with missing bid-ask prices and zero bids, options with zero open interest, or options with negative bid-ask spreads. To ensure that our results are not driven by misleading prices, we follow Conrad et al. (2013) and exclude options that do not satisfy the usual option price bounds, and options with less than 7 days to maturity. Since the estimation requires the implied volatility we exclude options with missing implied volatility. Following Bakshi et al. (2003) we restrict the sample to out-of-the-

\footnotetext{
${ }^{2}$ Data on all the standard pricing factors is obtained from the Kenneth French's website http://mba.tuck. dartmouth.edu/pages/faculty/ken.french/index.html.

${ }^{3}$ Consistent with previous literature, we remove negative book values. Also, book value is only observed at an annual frequency, and the only daily variability for the book-to-market comes from the changes in total market capitalization. Thus, since market capitalization may decrease to very small values for some distressed firms, there may be very large outliers for the book-to-market ratio. For this reason, we choose to winsorize the book-to-market ratio on a $99 \%$ level.
} 
money options. Finally, following Bollerslev et al. (2014) we restrict our estimation to options with days-to-maturity of 8 to 45 days.

Individual equity options are American, and the early exercise premium may confound our results. To avoid this issue, we use the implied volatilities of each option provided by OptionMetrics. These implied volatilities are computed using a proprietary algorithm that is based on the Cox et al. (1979) model, and account for the early exercise premium. Using these implied volatilities, we can treat the option prices obtained through the Black and Scholes formula as being European.

For the estimation of the market risk-neutral expected variance, we rely on market option prices obtained from the IvyDB OptionMetrics database for the period of January 1996 to December 2015. In contrast to individual equity options, market options are European and we do not need to worry about the early exercise premium. However, for the estimation of the market risk-neutral expected variance, we use the same methodology as for individual equities and make use of the market implied volatilities provided by OptionMetrics to infer the European option prices by the Black and Scholes formula. We apply the same filters for this data as for the individual equity option data. We also obtain data on the VIX index from the CBOE database for the period from January 1996 to December 2015.

Finally, we merge the option data set with the CRSP daily stock data following Appendix A.1 in Duarte et al. (2006). Consistent with the cross-sectional asset pricing literature, we focus only on firms listed on the NYSE, AMEX and NASDAQ that have CRSP share codes of 10 and 11.

Due to the filter that we use and the fact that many companies do not have traded options in our earlier sample, the cross-section of estimated firms' risk-neutral variance varies significantly during the sample period. Since the firms' variance risk premium is a function of the risk-neutral variance, the size of the cross-section of firms' variance risk premium also varies significantly during the sample period. In January 1996 the cross-section of firms' variance risk premium contains 426 firms, while at the end of the sample in December 2015 the cross-section grows significantly to 1245 firms. The average size of the cross-section of firms' variance risk premium throughout our sample is approximately 898 . 


\subsection{Descriptive Statistics}

Figure 1 plots the cross-sectional distribution of firm size for four key months throughout our sample period: January 1996 (beginning of the sample), November 2001 (IT crisis), September 2008 (global financial crisis) and December 2015 (end of the sample). These plots divide the range of the logarithm of market capitalization into 20 equal-length bins. In each of the selective four months, the firm size varies from few millions to hundreds of billions. Thus, our sample contains both small and large firms, covering a well-balanced size range.

Our descriptive statistics for the firm variance risk premia focus on the cross-sectional quantiles as for them we observe a full time-series. In Table 1, we present a set of summary statistics for risk-neutral expected realized variance $\left(\mathbb{E}^{\mathbb{Q}}[R V], \mathbb{E}^{\mathbb{Q}}\left[R V^{b}\right], \mathbb{E}^{\mathbb{Q}}\left[R V^{g}\right]\right)$, real-world expected realized variance $\left(\mathbb{E}[R V], \mathbb{E}\left[R V^{b}\right], \mathbb{E}\left[R V^{g}\right]\right)$, firm variance risk premium $\left(V R P, V R P^{g}, V R P^{b}\right)$, and some firm characteristics including illiquidity $(I L L I Q)$, individual skewness $(S K E W)$, idiosyncratic volatility $(I V O L)$, book-to-market ratio $(B / M)$, size (Size), past twelve-month cumulative excess returns (P12M) and past one-month returns (P01M). For the time-series of the cross-sectional $5^{\text {th }}, 50^{\text {th }}$ and $95^{\text {th }}$ quantiles of each of these variables, we report the mean, minimum, maximum, standard deviation, skewness and kurtosis.

Table 1 shows that the median values of the bad, the good and the total variance risk premia, as well as the signed jump risk premium are positive on average, equal to $29.76,8.98,18.70$ and 41.27 percent-squared, respectively. This confirms that the variance risk premium interpretations that we discussed in Section 2.1 hold on average for more than $50 \%$ of the firms in our sample. The median value of firm illiquidity $(I L L I Q)$ has a mean of 0.0048 which is comparable to values reported in Amihud (2002), and is also positively skewed with excess kurtosis. The median value of firm risk-neutral skewness $(S K E W)$ is on average negative, equal to -0.51 , and in the same range as values reported by Conrad et al. (2013) who analyze the relationship between skewness and expected returns. The median value of firm idiosyncratic volatility $(I V O L)$ is $2.04 \%$ on average and also compares well with the figures of Hou and Loh (2016) who propose a simple methodology to evaluate a large number of potential explanations for the idiosyncratic volatility puzzle.

Table 2 shows the time-series average of the cross-sectional correlations between firm-level variables. Not surprising, since bad and good variances equally contribute to total variance, the former 
tend to rank stocks similarly as the latter, leading to high cross-sectional correlations of expected bad and good realized variances with the expected total realized variance. These correlations are 0.87 and 0.81 respectively under the real-world density, while they are as high as 0.99 and 0.96 respectively under the risk-neutral density. Their strong cross-sectional correlation with the expected total variance make expected bad and good realized variances fairly well correlated in the cross-section, with correlation values of 0.47 under the real-world measure and as high as 0.92 under the risk-neutral measure. Also as expected, since the total variance risk premium is the difference between the bad and the good variance risk premia, total VRP is positively correlated to bad VRP and negatively correlated to good VRP in the cross-section, with correlation values of 0.86 and -0.70 respectively. Similarly, since the signed jump risk premium is the sum of the bad and the good variance risk premia, JRP is positively correlated to bad VRP and good VRP in the cross-section, with correlation values of 0.78 and 0.28 respectively.

Bad VRP and good VRP have a mild cross-sectional correlation of -0.30 , while total VRP and JRP have a cross-sectional correlation of 0.42. This is a direct consequence of bad VRP having a much larger cross-sectional dispersion compared to good VRP as illustrated in Table 1. Interestingly, VRP measures and JRP show very little cross-sectional correlations with other firm characteristics, with absolute correlation values not exceeding 0.10 except for correlations of good VRP and JRP with idiosyncratic volatility, which amount to 0.17 and 0.21 respectively. This observation is particularly meaningful as it suggests ruling out potential multicollinearity issues that may affect statistical inference in subsequent empirical tests, for example in cross-sectional regressions of excess returns on variance risk premium and other firm characteristics that are conducted in Section 4.3.

Table 3 summarizes the descriptive statistics of market-wide factors that will be controlled for in subsequent cross-sectional analyses of the relationship between expected stock returns and variance risk premium. The market bad VRP is on average 13.83 in monthly percentage-squared terms, with a standard deviation of 15.31. The market bad VRP dominates the good VRP, which amounts to a tiny 0.61 on average, ${ }^{4}$ leading to an average market total VRP value of 13.20 with

\footnotetext{
${ }^{4}$ This may suggest that the average investor is almost indifferent about fluctuations in market good variance while she does care about fluctuations in market bad variance and would like to insure against them. In a sense, these statistics also corroborate the findings of Feunou et al. (forthcoming) showing that market bad VRP is the most important component of the market total VRP.
} 
a standard deviation of 17.05. For comparison, the mean and standard deviation of market total VRP reported by Bollerslev et al. (2009) are respectively 18.30 and 15.13. Also, we observe that the dynamic of market bad VRP is very different from that of the good. For instance, market bad VRP is twice more volatile than that of the good; the skewness of market bad VRP is almost twice as large as that of the good; the kurtosis of market bad VRP is four times smaller than that of the good; and finally market bad VRP is more persistent with a first-order autocorrelation coefficient of 0.80 compared to the good's much lower autocorrelation of 0.49 . The market risk-neutral skewness is negative on average with a value of -1.96 , and this is consistent with values reported in previous studies, for example -1.26 in Bakshi et al. (2003).

Figure 2 plots market bad VRP on the right y-axis and month-by-month quantiles of firm bad VRP on the left y-axis. All variables are reported in monthly squared percentage terms. To compare the dynamic features between firm bad VRP quantiles to market bad VRP, the scale of firm level is 10 times larger than that of market level. In most months, market bad VRP and median firm bad VRP are both above zero. However, the 25th percentile of firm bad VRP is mostly negative, unless during great market downturns, such as the 1998 Long-Term Capital Management (LTCM) crisis, the aftermath of the dot-com bubble and the mild economic recession in the early 2000s, the 2008-09 recent financial crisis, the 2011-12 European debt crisis and the Chinese stock market turbulence in late 2015. During these periods, the range of firm bad VRP becomes much wider than in normal calm periods while market bad VRP is low. Among all crisis periods, market bad VRP reaches its historical peaks of 60.23 in October 1998 during the LTCM crisis, 59.07 in September 2002 during the dot-com crash, and 98.83 in November 2008 during the recent financial crisis. The 75th percentile of firm bad VRP reaches one of its historical peaks of 307.26 in January 2001 during the dot-com crash and is relatively large between 1999 and 2003. In October 2008 during the financial crisis, the 75th percentile of firm bad VRP reaches its maximum value of 397.62.

\section{Results}

\subsection{Single Sorting}

We first analyze univariate portfolio sorts involving our estimates of firm variance risk premium. Results are displayed in Table 4, where in each panel firms are sorted into quintile portfolios based 
on a different characteristic among bad VRP, good VRP, total VRP and JRP. More specifically, at the end of each month, we sort firms into quintiles on the basis of their corresponding monthly average values for the characteristic under consideration. Quintile 1 thus contains the firms with values in the bottom $20 \%$ while quintile 5 contains firms with values in the top $20 \%$. Then, for each quintile we use end-of-month market capitalizations of the firms to form a value-weighted portfolio and measure its excess returns over the next month. ${ }^{5}$ For each quintile we report the cross-sectional average value of firm characteristics and as well as the portfolio average monthly excess returns and alpha, where alpha is computed relative to the five-factor model of Fama and French (2015).

Panel A of Table 4 shows that sorting firms on the basis of bad VRP results in a wide range of bad VRP values, the lowest quintile having a negative average value of -180.65 while the average value for the highest quintile amounts to 249.24. Following our discussion in Sections 2.1 and 2.3, the top quintile thus consists of firms whose downside risk tends to become extreme in bad times, while it is the contrary for firms in the bottom quintile. Interestingly, the average good VRP value is positive for all quintile portfolios based on bad VRP, equal to 90.82 for the lowest quintile and 29.85 for the highest quintile. The declining trend in average good VRP values from quintile 1 to quintile 5 is consistent with the negative cross-sectional correlation between bad VRP and good VRP reported in Table 2. Also consistent with their definitions is the increasing patterns of total VRP and JRP from the lowest to the highest quintile when firms are sorted based on bad VRP.

The main finding of the paper resides in that average excess returns and alpha are increasing from the bottom quintile to the top quintile portfolio when firms are sorted on bad VRP. The average monthly excess return of the lowest quintile portfolio is $0.06 \%$ and amounts to $1.14 \%$ for the highest quintile portfolio, thus a high-minus-low difference of $1.08 \%$, or $12.96 \%$ when annualized. As argued in Section 2.3, the rationale for this is that investors are risk-averse and prefer firms in the lowest quintile because their downside risk tends to disappear in bad times, and investors are happy to face no insurance costs against such downside risk precisely when they are worse off, are then willing to pay more for such assets thus accepting a low premium to invest in them. To the contrary, firms in the highest quintile are disliked by investors since their downside risk tends to be severe in bad times. Investors having to incur high insurance costs against such downside

\footnotetext{
${ }^{5}$ This approach of measuring post-ranking excess returns in portfolio sorts avoids spurious effects and is used extensively in the literature, e.g., Fama and French (1993), Ang et al. (2006b), and Chang et al. (2013) among others.
} 
risk when they are already worse off are then willing to pay less for such assets, thus requiring a large premium to invest in them. The risk-adjusted performance of quintile portfolios as measured by their alpha confirms that on average the top quintile portfolio, with a positive alpha of $0.71 \%$, performs better than the bottom quintile portfolio, which has a negative alpha of $-0.76 \%$, thus a high-minus-low difference of $1.47 \%$, or $17.64 \%$ when annualized. As shown in Panel A of Table 4, these high-minus-low differences are statistically significant at the highest conventional level of confidence.

In Panel B of Table 4, firms are similarly sorted into quintiles on the basis of good VRP, resulting in a wide range of good VRP values from -62.18 on average for the bottom quintile to 197.72 on average for the top quintile. In this case, the lowest quintile is made of firms which upside potential tends to become immense in bad times, to the contrary of firms within the highest quintile. The declining pattern in average bad and total variance risk premia as well as the rising trend associated with average JRP from the lowest to the highest quintile when firms are sorted on good VRP are all consistent with the negative cross-sectional correlations of good VRP with bad VRP and total VRP on one hand, and its positive cross-sectional correlation with JRP on the other hand, as shown in Table 2 .

We also find that average excess returns and alpha are increasing from the lowest quintile to the highest quintile portfolio when firms are sorted on good VRP. The average monthly excess return of the lowest quintile portfolio is $0.17 \%$ and more than triple at $0.64 \%$ for the highest quintile portfolio, thus a high-minus-low difference of $0.48 \%$ albeit not statistically significant, or $5.76 \%$ when annualized. Following from our discussion in Section 2.3, the rationale for this finding resides in the fact that investors are potential-seeking and prefer firms in the bottom quintile since their upside potential tends to be so strong in bad times that investors need not require compensation for a possible shrink in such upside potential when they are worse off, and are then willing to pay a little more for such assets thus accepting a lower premium to invest in them. To the contrary, investors dislike firms in the top quintile since their upside potential tends to go downhill in bad times, to the point where investors would lack compensation for possible shrink in such upside potential when they are worse off, and are then willing to pay less for such assets thus accepting a higher premium to invest in them. The risk-adjusted performance of quintile portfolios as measured 
by their alpha confirms that on average the top quintile portfolio, with a positive alpha of $0.18 \%$, performs better than the bottom quintile portfolio, which has a negative alpha of $-0.38 \%$, thus a high-minus-low difference of $0.56 \%$, or $6.72 \%$ when annualized. As shown in Panel B of Table 4, this latest high-minus-low difference is statistically significant at the $95 \%$ level of confidence.

The remaining panels of Table 4 show results when firms are sorted on the basis of total VRP (in Panel C) and JRP (in Panel D). We recall that total VRP is the difference between bad VRP and good VRP, while JRP is their sum. In consequence, we may loosely interpret results from sorting on total VRP as measuring a net effect of bad VRP on good VRP, while results from sorting on JRP would measure a combined effect of bad VRP and good VRP. As shown in Panel C of Table 4 , the net effect is positive and highly statistically significant for both average excess returns and portfolio alpha. In other words, sorting stocks into quintile portfolios based on firm total VRP leads to an upward trend in average excess returns and a monotonically increasing pattern in alpha from the lowest quintile to the highest quintile. The average monthly excess return of the lowest quintile portfolio is $0.21 \%$ and amounts to $0.94 \%$ for the highest quintile portfolio, thus a highminus-low difference of $0.73 \%$, or $8.76 \%$ when annualized. Although much smaller, this is in line with Han and Zhou (2011) who report a high-minus-low average monthly returns of $1.84 \%$ from a much smaller sample both in the time series and the cross-sectional dimensions. Similarly, the top quintile portfolio, with a positive alpha of $0.42 \%$, performs better than the bottom quintile portfolio, which has a negative alpha of $-0.42 \%$, thus a high-minus-low difference of $0.84 \%$, or $10.08 \%$ when annualized.

Panel D of Table 4 finally shows that the combined effect leads to the largest heterogeneity in average excess returns and alpha across all panels of the table. This result is not surprising, as bad VRP and good VRP have similar effects on average excess returns and portfolio alpha in the crosssection, albeit with different levels of statistical significance. Sorting stocks into quintile portfolios based on firm JRP leads to a monotonically increasing pattern in both average excess returns and alpha from the lowest quintile to the highest quintile. The average monthly excess return of the lowest quintile portfolio is $0.05 \%$ and amounts to $1.43 \%$ for the highest quintile portfolio, thus a high-minus-low difference of $1.38 \%$, or $16.56 \%$ when annualized. Similarly, the top quintile portfolio, with a positive alpha of $1.05 \%$, performs better than the bottom quintile portfolio, which has a 
negative alpha of $-0.74 \%$, thus a high-minus-low difference of $1.78 \%$, or $21.36 \%$ when annualized.

To summarize, all measures (bad VRP, good VRP, total VRP and JRP) generate monotonic patterns or trends in the average returns of measure-sorted portfolios with statistically significant differences between the highest and the lowest quintile portfolios. Moreover, these patterns are in line with our predictive hypotheses, as discussed in Section 2.3. Although average excess returns and alpha have the same increasing pattern from the lowest quintile to the highest quintile portfolio in both univariate sorts, sorting stocks on firm bad VRP leads to a much larger and statistically significant heterogeneity in performance than sorting stocks on firm good VRP. ${ }^{6}$ All in all, the positive net cross-sectional effect resulting from total VRP analysis suggests that our results are mainly driven by bad VRP, rather than good VRP. This observation otherwise corroborates previous theoretical and empirical findings that investors focus more on the downside risk they face rather than the upside potential they would expect when investing in stocks (see for example Ang et al., 2006a and Farago and Tédongap, forthcoming, and references therein). Our subsequent analyses will try to measure cross-sectional variations in average excess returns and alpha that are due to variation in bad VRP unrelated to other risk measures put forward in the literature.

\subsection{Double Sorting}

Following our discussion in Section 2.3 where we interpret bad VRP as a measure of downside risk, given the extensive empirical literature investigating cross-sectional relationships between expected returns and downside risk (Ang et al., 2006a, Lettau et al., 2014, and Farago and Tédongap, forthcoming), and given possible correlations between different measures of downside risk, we ask whether variation in bad VRP that is unrelated to prominent measures of downside risk can still explain the cross-sectional variation in expected stock returns. From this end, and following Fama and French (1992), we first subdivide firms into five groups based on each of the multivariate exposures to the five generalized disappointment aversion (GDA) factors derived by Farago and Tédongap (forthcoming), ${ }^{7}$ and, within each group, we sort observations in quintiles based on firm bad VRP.

\footnotetext{
${ }^{6}$ The results also hold for value-weighted tercile and decile portfolios, as well as for equally-weighted portfolios. These untabulated results are available upon request.

${ }^{7}$ We simply focus on the paper by Farago and Tédongap (forthcoming) when controlling for existing downside risk measures, as the authors prove theoretically that downside risk measures in Ang et al. (2006a) and Lettau et al. (2014) are particular linear combinations of the multivariate GDA factor exposures.
} 
The five GDA factors depend on only two variables: the log market return, $r_{W}$, and changes in market conditional variance, $\Delta \sigma_{W}^{2}$. To measure the unobservable market conditional variance we use the real-world expected market realized variance computed from the variant of HAR-RV model introduced in Section 2.2. Following Farago and Tédongap (forthcoming, see their online appendix), we use short-window regressions to estimate the stocks' exposures (betas) to the GDA factors. Formally, for every month $t \geq 6$ in the sample, we use six months of daily data from month $t-5$ to month $t$ to run the time-series regression,

$$
R_{i, \tau}^{e}=\alpha_{i, t}+\beta_{i W, t} r_{W, \tau}+\beta_{i W \mathcal{D}, t} r_{W, \tau} \mathbb{I}\left(\mathcal{D}_{\tau}\right)+\beta_{i \mathcal{D}, t} \mathbb{I}\left(\mathcal{D}_{\tau}\right)+\beta_{i X, t} \Delta \sigma_{W, \tau}^{2}+\beta_{i X \mathcal{D}, t} \Delta \sigma_{W, \tau}^{2} \mathbb{I}\left(\mathcal{D}_{\tau}\right)+\varepsilon_{i, \tau}
$$

for each stock $i$ that has relevant data over the given period, where $R_{i, \tau}^{e}$ is the firm excess return, $r_{W, \tau}$ is the market factor, $r_{W, \tau} \mathbb{I}\left(\mathcal{D}_{\tau}\right)$ is the market downside factor, $\mathbb{I}\left(\mathcal{D}_{\tau}\right)$ is the downstate factor, $\Delta \sigma_{W, \tau}^{2}$ is the volatility factor, and $\Delta \sigma_{W, \tau}^{2} \mathbb{I}\left(\mathcal{D}_{\tau}\right)$ is the volatility downside factor, $\tau$ refers to daily observations over the six-month period and $t$ refers to the current month, $\mathcal{D}_{\tau}$ is the downside event defined as $\mathcal{D}_{\tau}=\left\{r_{W, \tau}-\left(\sigma_{W} / \sigma_{X}\right) \Delta \sigma_{W, \tau}^{2}<b\right\}$, where $\sigma_{W}=\operatorname{Std}\left[r_{W, \tau}\right]$ and $\sigma_{X}=\operatorname{Std}\left[\Delta \sigma_{W, \tau}^{2}\right]$ are the standard deviations of market log returns and changes in market variance, respectively, and where $b$ is chosen to match a downside probability of $16 \%$.

Double-sort results controlling for exposures to the five GDA factors are displayed in Table 5, where the last two rows in each panel report together with their t-statistics in parentheses the average excess returns spreads (5-1) between firms in the highest and the lowest quintile portfolios based on firm bad VRP. In all panels of the table, firms with high bad VRP outperform those with low bad VRP within all clusters of GDA factor exposures, with sizeable spreads ranging between $0.52 \%$ and $1.82 \%$, or equivalently $6.24 \%$ and $21.84 \%$ in annualized terms. Out of the twenty-five reported spreads, twenty-two are statistically significant at the $95 \%$ or higher confidence level, two at the $90 \%$ confidence level, and only one at a lower confidence level. This is strong evidence that cross-sectional variation in average excess returns reflects heterogeneity in firm bad VRP that is unrelated to heterogeneity in existing downside risk measures across stocks.

We also investigate whether asset pricing information incorporated in bad VRP is already accounted for by firm exposure to other systematic factors. To tackle this point, we consider two systematic factors for which variations are likely correlated to firm-level bad VRP, namely the 
market bad VRP (see Figure 2), and the market risk-neutral skewness. To measure firm exposure to market bad VRP, we start from the cross-sectional implications of the general equilibrium asset pricing model proposed by Bollerslev et al. (2009), featuring three factors: market excess returns, innovations in market conditional variance, and innovations in market variance of variance. Since the model also implies that market total VRP is solely determined by variance of variance, and given our total VRP decomposition into a bad and good component, we substitute out the variance of variance factor by the market bad and good VRP and measure firm exposure to market bad VRP from the resulting four-factor model. Formally, at the end of each month $t \geq 6$ in the sample, we run the following time-series regression:

$$
R_{i, \tau}^{e}=\alpha_{i, t}+\beta_{i, t}^{m} R_{m, \tau}+\beta_{i, t}^{b a d} \Delta V R P_{m, \tau}^{b}+\beta_{i, t}^{g o o d} \Delta V R P_{m, \tau}^{g}+\beta_{i, t}^{v i x} \Delta V I X_{m, \tau}^{2}+\varepsilon_{i, \tau}
$$

using six months of daily data from month $t-5$ to month $t$, where $\tau$ refers to daily observations over the six-month period, $R_{i, t}^{e}$ and $R_{m, t}$ are firm and market excess returns, respectively, $\Delta V I X_{m, \tau}^{2}$ are changes in the $V I X^{2}$ index, and $\Delta V R P_{m, \tau}^{b}$ and $\Delta V R P_{m, \tau}^{g}$ are changes in market bad VRP and market good VRP, respectively.

Firm exposure to market risk-neutral skewness are calculated following Chang et al. (2013), i.e., at the end of each month $t \geq 6$ in the sample, we run the following regression using six months of daily data from month $t-5$ to month $t$ :

$$
R_{i, \tau}^{e}=\alpha_{i, t}+\beta_{i, t}^{m} R_{m, \tau}+\beta_{i, t}^{s k e w} \Delta S K E W_{m, \tau}+\varepsilon_{i, \tau}
$$

where $\tau$ refers to daily observations over the six-month period, $R_{i, \tau}^{e}$ and $R_{m, \tau}$ are firm and market excess returns, respectively, and $\triangle S K E W_{m, \tau}$ are changes in market risk-neutral skewness $S K E W_{m, \tau}$ estimated following Bakshi et al. (2003) by using prices of quadratic, cubic and quartic contracts on the S\&P 500 index computed from available option data (see Appendix A).

Double-sort results controlling for exposures to market bad VRP and market risk-neutral skewness are displayed in Table 6, where the last two rows in each panel report together with their t-statistics in parentheses the average excess returns spreads (5-1) between firms in the highest and the lowest quintile portfolios based on firm bad VRP. As shown in both panels of the table, 
controlling for exposures to market bad VRP and market skewness does not hinder the ability of firm bad VRP in explaining cross-sectional differences in average excess returns across stocks. In all panels of the table, firms with high bad VRP outperform those with low bad VRP within all clusters of exposures to market bad VRP and market risk-neutral skewness, with sizeable spreads ranging between $0.99 \%$ and $1.80 \%$, or equivalently $11.88 \%$ and $21.60 \%$ in annualized terms. Out of the ten reported spreads, all are statistically significant at the $95 \%$ or higher confidence level. This again suggests that cross-sectional variation in average excess returns reflects heterogeneity in firm bad VRP that is unrelated to heterogeneity in various sources of systematic risk across stocks.

We finally use double-sort strategies to examine whether the asset pricing information carried by some popular firm characteristics studied throughout the literature do already account for the pricing information embedded in firm bad VRP. ${ }^{8}$ These other firm characteristics are illiquidity (Amihud, 2002), idiosyncratic volatility (Ang et al., 2006b), individual skewness (Conrad et al., 2013), and relative signed jump variation (Bollerslev et al., 2017) measured as

$$
R S J_{i, t}=\frac{R V_{i, t}^{g}-R V_{i, t}^{b}}{R V_{i, t}} .
$$

Appendix A describes how we measure the remaining firm characteristics from the data. The hypothesis is that if firm bad VRP was priced simply because bad VRP captures the effects of illiquidity, idiosyncratic volatility, firm-level skewness, or relative signed jump variation, then controlling for these other firm characteristics would yield weak or insignificant cross-sectional variation in average returns across stocks sorted on firm bad VRP.

Double-sort results controlling for other firm characteristics are displayed in Table 7, where the last two rows in each panel report together with their t-statistics in parentheses the average excess returns spreads (5-1) between firms in the highest and the lowest quintile portfolios based on firm bad VRP. As illustrated in all panels of the table, the explanatory power of firm bad VRP for cross-sectional differences in average excess returns across stocks is unaffected after controlling for other firm characteristics. In all panels of the table, firms with high bad VRP outperform those with low bad VRP within all clusters, with sizeable spreads ranging between $0.69 \%$ and $2.31 \%$, or

\footnotetext{
${ }^{8}$ We treat bad VRP as a firm characteristic as there isn't any observable market-wide factor such that firm bad VRP is equal to the firm factor loading (or beta), that is such that bad VRP measures systematic risk associated with that factor.
} 
equivalently $8.28 \%$ and $27.72 \%$ in annualized terms. Out of the twenty reported spreads, eighteen are statistically significant at the $95 \%$ or higher confidence level, and only two at a lower confidence level. In summary, cross-sectional variation in average excess returns reflects heterogeneity in firm bad VRP that is unrelated to heterogeneity in popular firm characteristics investigated in the asset pricing literature.

\subsection{Fama-MacBeth Regressions}

While previous portfolio sort analyses provide strong evidence that firm bad VRP is significantly priced in the cross-section of stock returns, they are incomplete because, for example, we cannot directly assess by how much we would expect an increase in expected returns on average by investing in a new stock with bad VRP that is one standard deviation higher than an old one. This instead can be achieved by estimating the sensitivity of expected returns to firm bad VRP through crosssectional regressions, eventually controlling for various cross-sectional effects. From this end, we follow the procedure introduced by Fama and MacBeth (1973) and run a series of cross-sectional regressions using individual firms.

While it is common in the literature to use portfolios as base assets in Fama-MacBeth regressions, our choice to use individual stocks follows from Ang et al. (2010) and Gagliardini et al. (2016), who discuss cross-sectional tests using a large cross-section of individual stocks versus fewer portfolios. They prove theoretically and observe empirically that using portfolios destroys important information necessary for obtaining efficient estimates of the cross-sectional risk premiums. Their main argument is that individual stocks provide a much larger dispersion in characteristics and exposures, an important prerequisite to cross-sectional tests. Creating portfolios based on a characteristic such as, for example, bad VRP, may exaggerate its effect on expected returns while downplaying the effect of other firm characteristics or factor exposures. Thus, using individual stocks as base assets will yield more conservative estimates than using portfolios.

We structure our cross-sectional regression results in two groups that are analyzed separately. We start by discussing results from Table 8, where we control for systematic risk in Fama-MacBeth regressions of individual firm excess returns on firm variance risk premium. There are seven different model specifications in the table. In Model I, the firm total VRP is solely used to explain 
differences in individual stock expected returns. The cross-sectional relationship of Model I appears statistically insignificant at the $95 \%$ confidence level. The price of VRP, i.e., the slope coefficient on the total VRP in the cross-sectional regression, is 0.05 , with a t-statistic of 1.69 .

Bearing in mind that total VRP is the difference between bad VRP and good VRP, Model II departs from Model I by using both bad VRP and good VRP instead, thus separating downside risk and upside potential when using variance risk premium to explain the diversity in expected returns across individual stocks. The result is striking. It shows that disentangling the two cross-sectional effects from firm bad VRP and good VRP proves meaningful, ${ }^{9}$ and both effects are statistically significant at the $99 \%$ confidence level. The price of downside risk, i.e., the slope coefficient on the bad VRP in the cross-sectional regression, is 0.17 with a t-statistic of 3.84. Similarly, the price of upside potential, i.e., the slope coefficient on the good VRP in the cross-sectional regression, is 0.27 with a t-statistic of 3.32 .

The remaining specifications in Table 8, i.e., from Model III to Model VII, all start from Model II and expand the set of risk measures used to jointly explain heterogeneity in average returns across individual stocks. When adding alternately the CAPM beta (Model III), firm exposure to market skewness (Model IV), firm exposures to market variance and market variance risk premium (Model V), Carhart factor exposures (Model VI), and GDA factor exposures (Model VII), the statistical significance and the economic magnitudes for the prices of bad VRP and good VRP increase.

We now turn to the results in Table 9 where we control for other firm characteristics in FamaMacBeth regressions of individual firm excess returns on firm variance risk premium. There are four specifications in the table. Observe that Model I and Model II are the same as in Table 8 and are repeated for convenience. Model VIII adds the relative signed jump variation to bad VRP and good VRP, while Model IX expands Model II with a considerably larger panel of other firm characteristics. Once again, accounting for these multiple cross-sectional effects does not erode the statistical significance and the economic magnitudes for the prices of bad VRP and good VRP. All

\footnotetext{
${ }^{9}$ This is similar to the findings of Campbell and Vuolteenaho (2004) and Bansal et al. (2005). Starting from the CAPM and the consumption-based CAPM, respectively, the authors decompose the total asset risk into a cash flow component and a discount rate component. Empirically, they find weak evidence that total asset risk is priced, while having strong evidence for priced cash flow risk. Given these findings, Bansal et al. (2005) argue that, when multiple sources of risk are priced, solely using the combined exposure in cross-sectional regression can produce a "tilt," and the estimated price of risk can be insignificant. If, however, one extracts the different components of risk, then they should appropriately measure differences in risk premia attributable to the different sources. Likewise, total VRP, in the presence of downside risk and upside potential, may fail to account for the differences in the risk premia across assets, which the bad VRP may explain.
} 
in all, neither systematic risk nor other firm characteristics do seem to drive out any of the two components of firm variance risk premium, and if anything, it is the other way around.

Finally, to quantitatively assess the economic significance of downside risk and upside potential in our setting, we start by computing the time-series averages of monthly cross-sectional standard deviations of firm-level bad VRP and good VRP. This yields 329.30 percent-squared for bad VRP and 249.45 for good VRP, which we multiply by the lowest and the largest values of estimated cross-sectional prices of bad VRP and good VRP, respectively. These lowest and highest values are designed based on all estimates from both Table 8 and Table 9. Our results suggest that a one-standard-deviation increase in bad VRP is associated with a 6.7-12.7\% rise in annualized expected stock returns. Likewise, a one-standard-deviation increase in good VRP is associated with an $8.1-18.3 \%$ rise in annualized expected stock returns.

\subsection{Additional Checks}

We perform a number of additional checks to verify the stability of our findings. These results can be found in the Online Appendix.

Logarithmic HAR-RV Model We estimate expected realized variances following the logarithmic version of the HAR-RV model where all variables in Equation (12) are replaced by their logarithms. The expected realized variance is thus obtained as the exponential of the expected log realized variance accounting for the Jensen's inequality adjustment. Using the logarithmic version of the HAR-RV model for the computation of the different measures of variance risk premium in the empirical part yields qualitatively similar findings.

Subsample Analysis We conduct two subsample analyses using data excluding the 2008 financial crisis (January 1996 - December 2006), and another analysis excluding the IT-crisis (January 2003 - December 2015). We also repeat our cross-sectional analyses for three subsamples obtained by dividing the firms in three groups based on their market capitalization: the bottom $30 \%$, the middle $40 \%$ and the top $30 \%$. All these analyses unanimously confirm the strongly significant positive cross-sectional relationship between expected stock returns and bad VRP within different subsamples. 
Portfolio Sorts versus Cross-Sectional Regressions The reader may finally wonder why Fama-MacBeth regressions reveal that good VRP is strongly connected to expected returns in the cross-section, while the evidence of this cross-sectional relationship from portfolio sorts is relatively weak. The interpretation is rather simple and comes from the omitted-variable bias occurring when model specification incorrectly leaves out one important explanatory variable. Because bad VRP and good VRP are both positive cross-sectional determinants of expected stock returns and are significantly negatively correlated, as shown in Table 2, omitting either variable would lead to understating the direct cross-sectional effect of the other variable. To check this, we conduct a bivariate portfolio exercise by unconditionally sorting individual stocks into $5 \times 5$ portfolios that are the intersections of 5 quintile portfolios formed on firm bad VRP and 5 quintile portfolios formed on firm good VRP. Our results show that the resulting 5-1 spreads are positive and highly statistically significant in both VRP dimensions. Most importantly, these spreads, which now account for both dimensions, are much larger compared to those obtained in previous univariate portfolio sorts where one of the two VRP dimensions is omitted. Nevertheless, accounting for both VRP dimensions in portfolio sorts that control for other cross-sectional effects would mean conducting at least a three-dimensional portfolio sort which is rather difficult to visualize.

\section{Conclusion}

We complement the growing literature analyzing time-series predictability of aggregate stock market returns by the variance risk premium by showing that heterogeneity in variance risk premium across stocks is associated with differences in expected returns in the cross-section. To this end, we decompose the variance premium of an individual firm's stock into a bad and good components and measure the premiums associated with their fluctuations. These bad and good variance risk premiums represent the cost for insuring against fluctuations in bad variance and the benefit compensating for fluctuations in good variance, and the total variance risk premium is the difference between the two. Our findings suggest that expected stock returns in the cross-section are positively related to the bad, the good and the total variance risk premiums, and this relationship being much stronger, highly statistically significant and more robust with the bad variance risk premium. Sorting stocks into portfolios based on their individual bad variance risk premium results 
in an economically large annualized risk-adjusted expected return spread between the stocks in the highest and lowest quintile portfolios of $17.6 \%$. The return spreads remain highly statistically significant and economically important in double-sort strategies and in Fama and MacBeth (1973) regressions controlling for other firm characteristics and various cross-sectional effects put forward in the empirical literature.

Crucially, our results point to the fact when analyzing the relationship between expected stock returns and individual firms' variance risk premium, it is imperative to decompose the variance risk premium into its upside and downside component. Bollerslev et al. (2014) find that the market variance risk premium predicts aggregate market returns with similar patterns for a range of countries. Thus, an interesting extension of our empirical analysis would be to expand the crosssection to include international firms and investigate if the cross-sectional effects documented in this article would survive at an international level. Another interesting empirical extension would be to examine the cross-section of variance risk premium and expected returns of other assets such as currencies and commodities from the same perspective. 


\section{A Measuring Firm Characteristics}

Illiquidity The measure of illiquidity that we use is taken from Amihud (2002) and is defined as

$$
I L L I Q_{i, t}=\frac{1}{\left|D_{i, t}\right|} \sum_{\tau \in D_{i, t}} \frac{\left|r_{i, \tau}\right|}{\operatorname{VOL} D_{i, \tau}},
$$

where $D_{i, t}$ is the set of days for which relevant data are available for stock $i$ in month $t,\left|D_{i, t}\right|$ is the cardinality of $D_{i, t},\left|r_{i, \tau}\right|$ is the daily absolute return for stock $i$, and $V O L D_{i, \tau}$ is the daily volume in dollars for stock $i$.

Idiosyncratic Volatility Following Ang et al. (2006b), we estimate firm idiosyncratic volatility for month $t$ as the standard deviation of the residuals from the daily time-series regression

$$
R_{i, \tau}^{e}=\alpha_{i, t}+\beta_{i, t}^{m} M K T_{\tau}+\beta_{i, t}^{s m b} S M B_{\tau}+\beta_{i, t}^{h m l} H M L_{\tau}+\varepsilon_{i, \tau}
$$

where $\tau$ refers to daily observations over month $t, R_{i, \tau}^{e}$ and $M K T_{\tau}$ are firm and market excess returns, respectively, $S M B_{\tau}$ and $H M L_{\tau}$ are the size and the value factor, respectively. Thus we define idiosyncratic volatility as

$$
I V O L_{i, t}=\sqrt{\frac{1}{\left|D_{i, t}\right|-1} \sum_{\tau \in D_{i, t}} \varepsilon_{i, \tau}^{2}}
$$

Market and Individual Skewness We measure market and individual skewness using firm option data. Following Bakshi et al. (2003), we define $V_{i, t}(\tau), W_{i, t}(\tau)$ and $X_{i, t}(\tau)$ as the time- $t$ prices of the 30-day quadratic, cubic and quartic contracts on the underlying firm $i$, respectively. Using the prices of these contracts, Bakshi et al. show that the risk-neutral skewness can be calculated as

$$
S K E W_{i, t}(\tau)=\frac{e^{r \tau} W_{i, t}(\tau)-3 \mu_{i, t}(\tau) e^{r \tau} V_{i, t}(\tau)+2 \mu_{i, t}(\tau)^{3}}{\left[e^{r \tau} V_{i, t}(\tau)-\mu_{i, t}(\tau)^{2}\right]^{3 / 2}},
$$

where $\mu_{i, t}(\tau)=e^{r \tau}-1-e^{-r \tau} V_{i, t}(\tau) / 2-e^{-r \tau} W_{i, t}(\tau) / 6-e^{-r \tau} X_{i, t}(\tau) / 24$, and $r$ is the risk-free rate. 


\section{References}

Amihud, Y. (2002), "Illiquidity and Stock Returns: Cross-section and Time-series Effects," Journal of Financial Markets, 5, 31-56.

Ang, A., Chen, J., and Xing, Y. (2006a), "Downside Risk," Review of Financial Studies, 19(4), 1191-1239.

Ang, A., Hodrick, R. J., Xing, Y., and Zhang, X. (2006b), "The Cross Section of Volatility and Expected Returns," Journal of Finance, 11(1), 259-299.

Ang, A., Liu, J., and Schwarz, K. (2010), "Using Stocks or Portfolios in Tests of Factor Models," Working Paper.

Bakshi, G., and Madan, D. (2000), "Spanning and Derivative-security Valuation," Journal of Financial Economics, 55, 205-238.

Bakshi, G., Kapadia, N., and Madan, D. (2003), "Stock Return Characteristics, Skew Laws, and the Differential Pricing of Individual Equity Options," Review of Financial Studies, 16(1), 101-143.

Bansal, R., and Yaron, A. (2004), "Risks for the Long Run: A Potential Resolution of Asset Pricing Puzzles," Journal of Finance, 59(4), 1481-1509.

Bansal, R., Dittmar, R. F., and Lundblad, C. T. (2005), "Consumption, Dividends, and the Cross Section of Equity Returns," Journal of Finance, 60(4), 1639-1672.

Barndorff-Nielsen, O. E., Kinnebrock, S., and Shephard, N. (2010) "Measuring downside risk: realised semivariance," in Volatility and Time Series Econometrics: Essays in Honor of Robert F. Engle, eds. T. Bollerslev, and J. Russell, and M. Watson, Oxford: Oxford University Press, pp. 117-136.

Bawa, V. S., and Lindenberg, E. B. (1977), "Capital Market Equilibrium in a Mean-lower Partial Moment Framework," Journal of Financial Economics, 5(2), 189-200.

Bekaert, G., Engstrom, E., and Ermolov, A. (2015), "Bad Environments, Good Environments: A Non-Gaussian Asymmetric Volatility Model," Journal of Econometrics, 186(1), 258-275.

Black, F., and Scholes, M. (1973), "The Pricing of Options and Corporate Liabilities," Journal of Political Economy, 81(3), 637-654.

Bollerslev, T. (1986), "Generalized Autoregressive Conditional Heteroskedasticity," Journal of Econometrics, 31, 307-328.

Bollerslev, T., Marrone, J., Xu, L., and Zhou, H. (2014), "Stock Return Predictability and Variance Risk Premia, Statistical Inference and International Evidence," Journal of Financial and Quantitative Analysis, 3(49), 633-661.

Bollerslev, T., Tauchen, G., and Zhou, H. (2009), "Expected Stock Returns and Variance Risk Premia," Review of Financial Studies, 22(11), 4463-4492.

Bollerslev, T., Zhengzi, L. S., and Zhao, B. (2017), "Good Volatility, Bad Volatility, and the CrossSection of Stock Returns," Working Paper. 
Bonomo, M., Garcia, R., Meddahi, N., and Tédongap, R. (2015), "The Long and the Short of the Risk-return Trade-off," Journal of Econometrics, 187(2), 580-592.

Campbell, J., and Vuolteenaho, T. (2004), "Bad Beta, Good Beta," American Economic Review, $94(5), 1249-1275$.

Carr, P., and Wu, L. (2009), "Variance Risk Premiums," Review of Financial Studies, 22(3), 13111341.

Chang, B. Y., Christoffersen, P., and Jacobs, K. (2013), "Market Skewness Risk and the Cross Section of Stock Returns," Journal of Financial Economics, 107(1), 46-68.

Conrad, J., Dittmar, R. F., and Ghysels, E. (2013), "Ex Ante Skewness and Expected Stock Returns," Journal of Finance, 68 (1), 85-124.

Corsi, F. (2009), "A Simple Approximate Long-Memory Model of Realized Volatility," Journal of Financial Econometrics, 7(2), 174-196.

Cox, J. C., Ross, S. A., and Rubinstein, M. (1979), "Option Pricing: A Simplified Approach," Journal of Financial Economics, 7(3), 229-263.

Daniel, K., and Titman, S. (1997), "Evidence on the Characteristics of Cross Sectional Variation in Stock Returns," Journal of Finance, 52(1), 1-33.

_ (2012), "Testing Factor-Model Explanations of Market Anomalies," Critical Finance Review, $1(1), 103-139$.

Drechsler, I., and Yaron, A. (2011), "What's Vol Got to Do with It," The Review of Financial Studies, 24(1), 1-45.

Duarte, J., Lou, X., and Sadka, R. (2006), "Can Liquidity Events Explain the Low-Short-Interest Puzzle? Implications from the Options Markets," Working Paper.

Fama, E. F., and French, K. R. (1992), "The Cross-Section of Expected Stock Returns," Journal of Finance, 47(2), 427-465.

_ (1993), "Common Risk Factors in the Returns on Stocks and Bonds," Journal of Financial Economics, 33, 3-56.

_ (2015), "A Five-factor Asset Pricing Model," Journal of Financial Economics, 116, 1-22.

Fama, E. F., and MacBeth, J. D. (1973), "Risk, Return, and Equilibrium: Empirical Tests," Journal of Political Economy, 81(3), 607-636.

Farago, A., and Tédongap, R. (forthcoming), "Downside Risks and the Cross-Section of Asset Returns," Journal of Financial Economics.

Feunou, B., Jahan-Parvar, M. R., and Tédongap, R. (2013), "Modeling Market Downside Volatility," Review of Finance, 17(1), 443-481.

- (2016), "Which Parametric Model for Conditional Skewness?," The European Journal of Finance, $22(13), 1237-1271$. 
Feunou, B., Jahan-Parvar, M.R., and Okou, C. (forthcoming), "Downside Variance Risk Premium," Journal of Financial Econometrics.

Gagliardini, P., Ossola, E., and Scaillet, O. (2016), "Time-Varying Risk Premium in Large CrossSectional Equity Data Sets," Econometrica, 84(3), 985-1046.

González-Urteaga, A., and Rubio, G. (2016), "The Cross-Sectional Variation of Volatility Risk Premia," Journal of Financial Economics, 119(2), 353-370.

Gul, F. (1991), "A Theory of Disappointment Aversion," Econometrica, 59(3), 667-86.

Han, B., and Zhou, Y. (2011), "Variance Risk Premium and Cross-Section of Stock Returns," Working Paper.

Held, M., Kapraun, J., and Omachel, M. (2016), "Up- and Downside Variance Risk Premia in Global Equity Markets," Technical Report, Otto-von-Guericke University Magdeburg, Faculty of Economics and Management.

Hou, K., and Loh, R. K. (2016), "Have We Solved the Idiosyncratic Volatility Puzzle?," Journal of Financial Economics, 121(1), 167 - 194.

Jiang, G. J., and Tian, Y. S. (2005), "The Model-Free Implied Volatility and Its Information Content," Review of Financial Studies, 18(4), 1305-1342.

Kahneman, D., and Tversky, A. (1979), "Prospect Theory: An Analysis of Decision under Risk," Econometrica, 47(2), 263-91.

Kilic, M., and Shaliastovich, I. (forthcoming), "Good and Bad Variance Premia and Expected Returns," Management Science.

Lettau, M., Maggiori, M., and Weber, M. (2014), "Conditional Risk Premia in Currency Markets and Other Asset Classes," Journal of Financial Economics, 114(2), 197-225.

Markowitz, H. (1959) Portfolio Selection, New Haven, New Haven: Yale University Press.

Newey, W.K., and West, K.D. (1987), "A Simple, Positive Semi-definite Heteroskedasticity and Autocorrelation Consistent Covariance Matrix," Econometrica, 55, 703-708.

Patton, A., and Sheppard, K. (2015), "Good Volatility, Bad Volatility: Signed Jumps and the Persistence of Volatility," Review of Economics and Statistics, 97(3), 683-697.

Quiggin, J. (1982), "A Theory of Anticipated Utility," Journal of Economic Behavior E Organization, 3(4), 323-343.

Routledge, B. R., and Zin, S. E. (2010), "Generalized Disappointment Aversion and Asset Prices," Journal of Finance, 65(4), 1303-1332.

Roy, A. D. (1952), "Safety First and the Holding of Assets," Econometrica, 20, 431-449.

Segal, G., Shaliastovich, I., and Yaron, A. (2015), "Good and Bad Uncertainty: Macroeconomic and Financial Market Implications," Journal of Financial Economics, 117(2), 369-397. 


\section{Figure 1: Distribution of Market Capitalization}

In this figure we plot the distribution of market capitalization across firms during the beginning and end of our sample, January 1996 and December 2015, respectively. We also plot the market capitalization distribution during two crises in our sample. One month at the end of the NBER Recession related to the IT-crisis (November 2001), and the second the month of the Lehman Brothers collapse (September 2008). The values in the x-axis are in USD millions. We also report the minimum, maximum, 5th and 95th quantiles of the average of market capitalization. In total we have 5150 firms in our sample.

\section{Distribution of Market Capitalization}
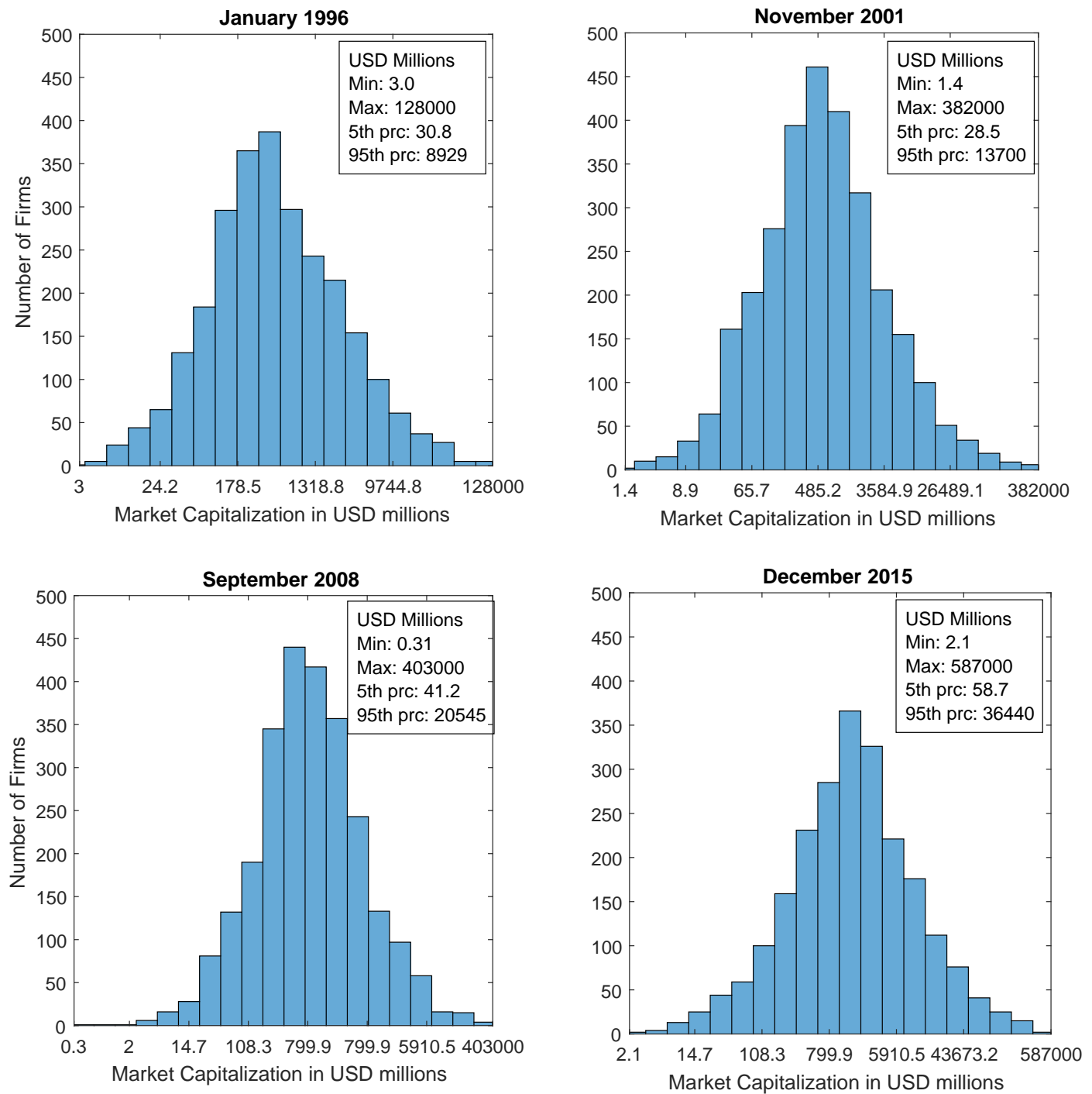
Figure 2: Firm Bad VRP Quantiles and Market Bad VRP

In this figure we plot the cross-sectional 25th, 50th and 75th quantiles of firms' bad variance risk premium $\left(V R P^{b}\right)$, and the time series of the market bad variance risk premium $\left(M V R P^{b}\right)$. The left hand y-axis shows the values of the $V R P^{b}$ quantiles, while the right hand y-axis shows the values for the $M V R P^{b} . V R P^{b}$ and $M V R P^{b}$ are in squared percentage terms. Sample period January 1996 - December 2015.

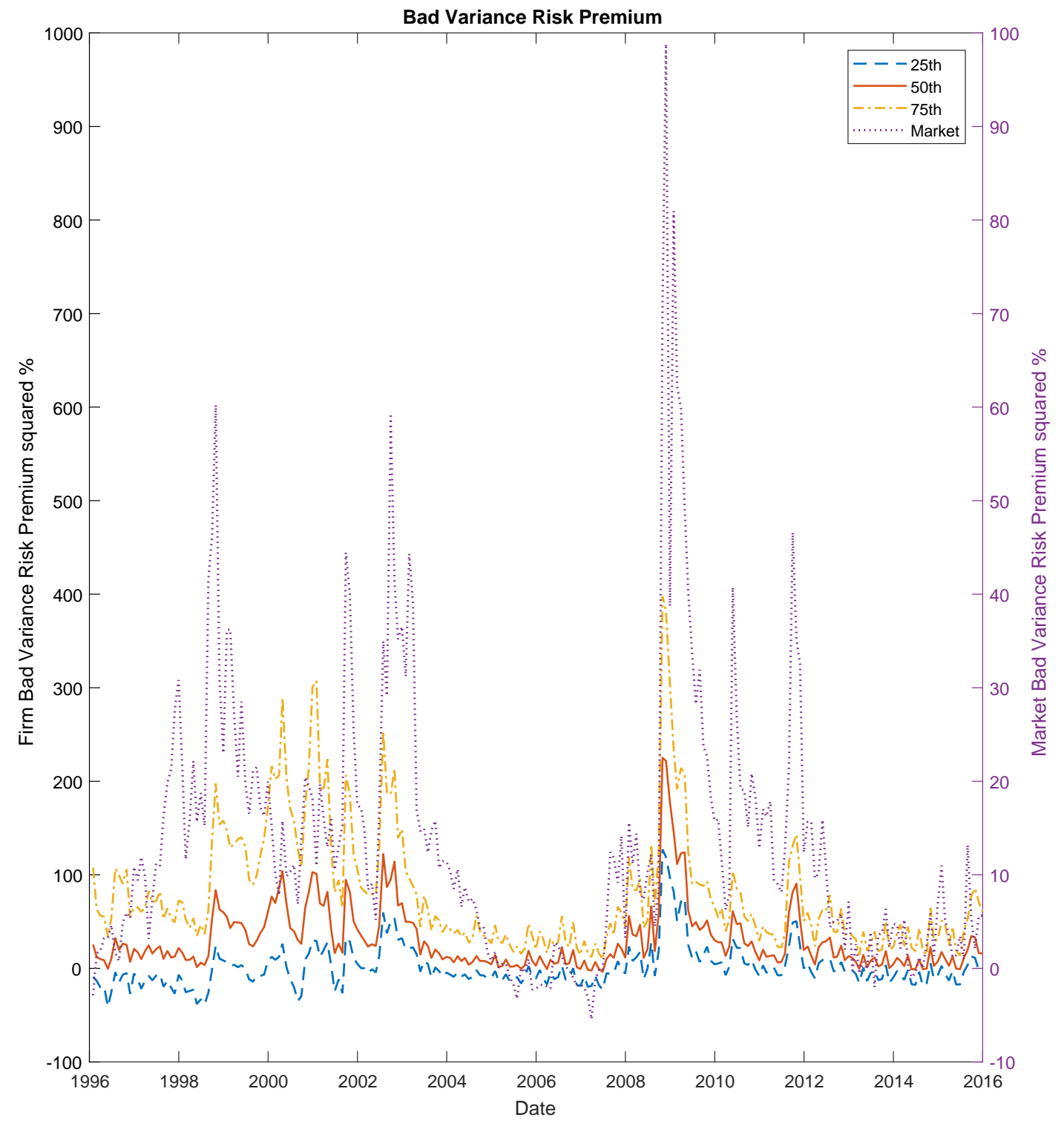




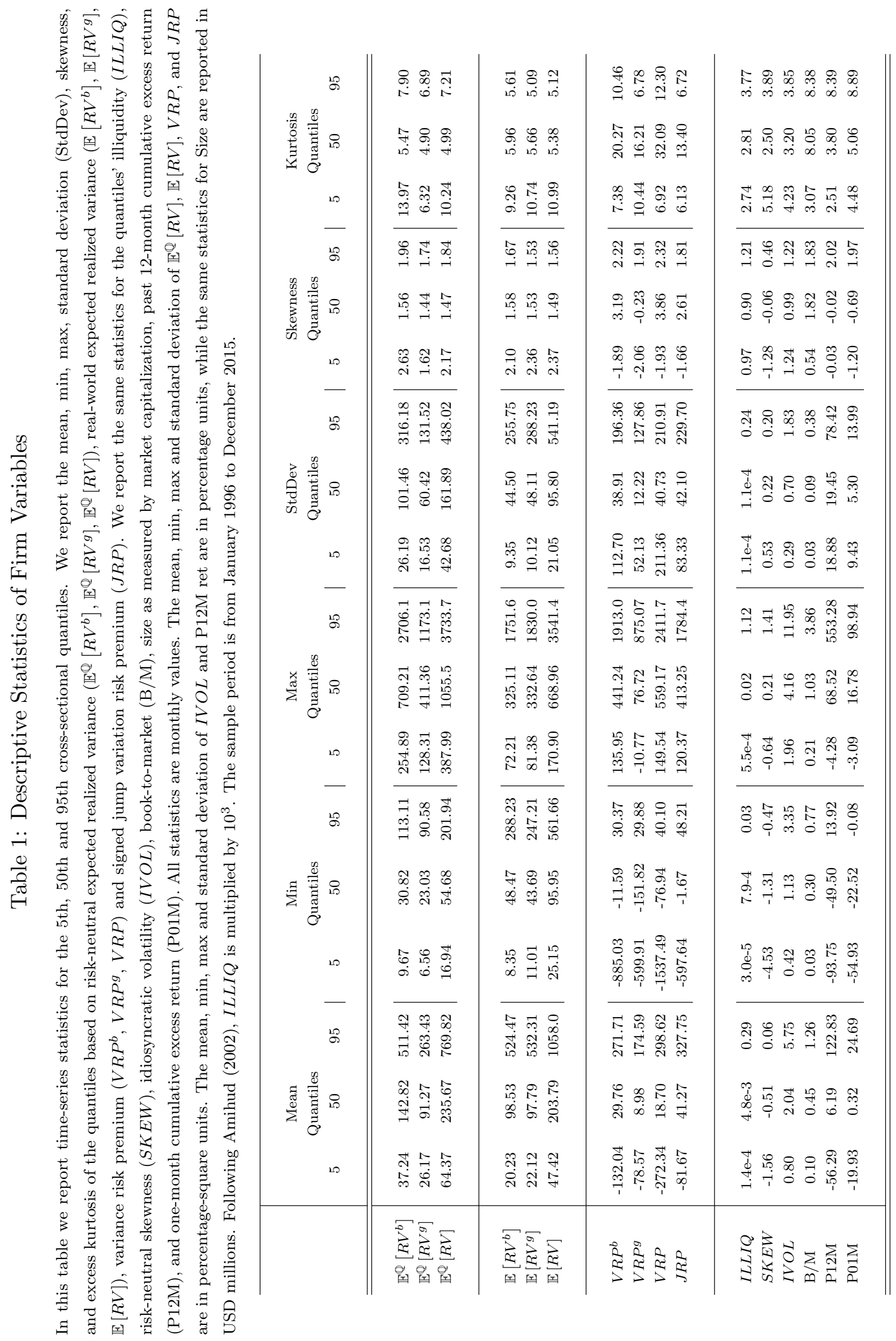




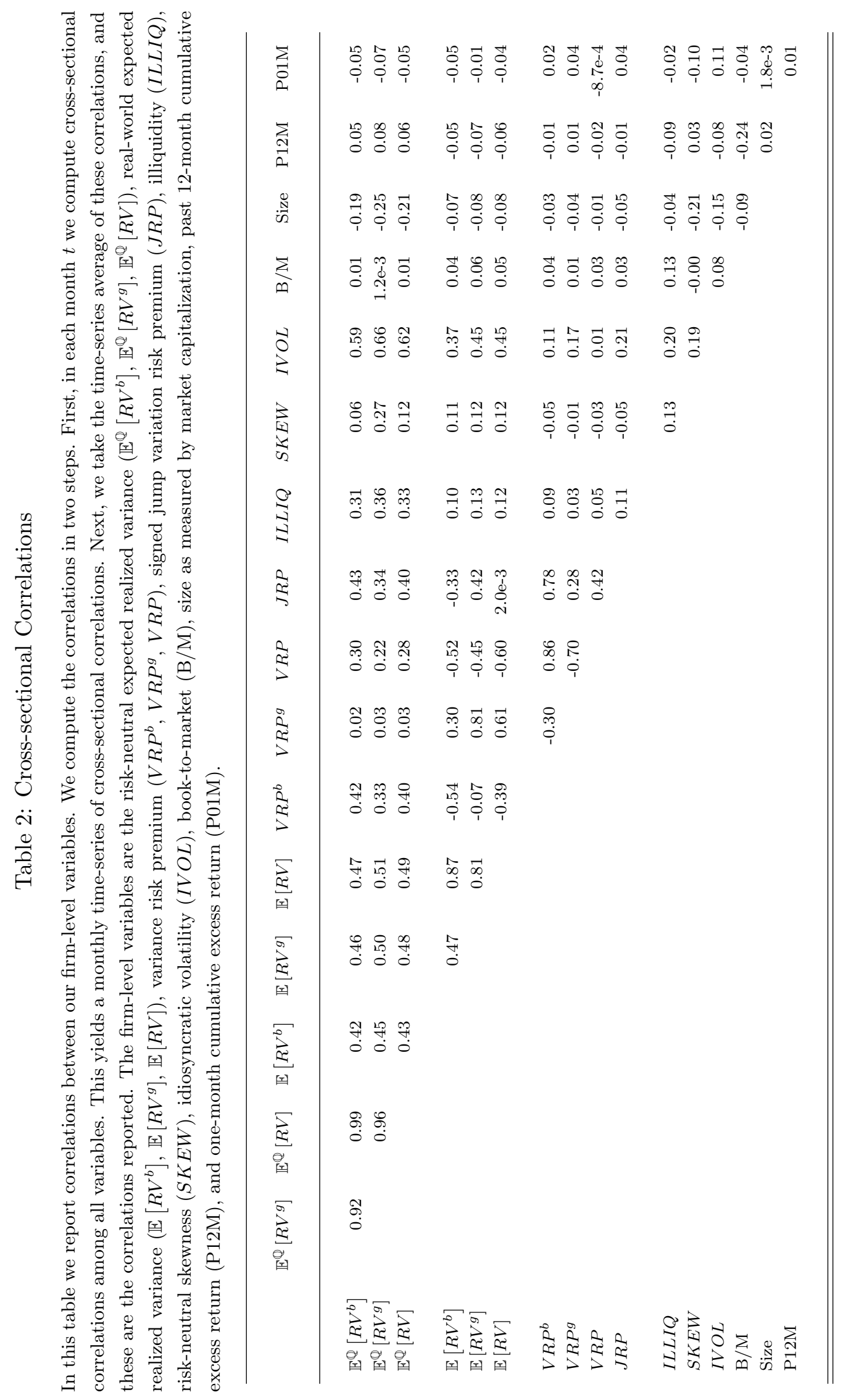


Table 3: Descriptive Statistics Control Variables

In this table we report the mean, median, minimum, maximum, standard deviation (StdDev), skewness, kurtosis and persistence $(\mathrm{AR}(1))$ for the market variance risk premium $\left(V R P_{m}^{b}, V R P_{m}^{g}, V R P_{m}\right)$, market signed jump variation risk premium $\left(J R P_{m}\right)$, and the market risk neutral skewness $\left(S K E W_{m}\right)$. The total, good and bad market variance risk premium is computed using S\&P500 returns and option data in a similar fashion to the firm $V R P$. To estimate the market risk neutral skewness we follow Bakshi et al. (2003) and define $V_{m, t}(\tau), W_{m, t}(\tau)$ and $X_{m, t}(\tau)$ as the time $t$ price of the $\tau$-maturity (days-to-maturity) quadratic, cubic and quartic contracts on the S\&P500, respectively. Using the prices of these contracts, Bakshi et al. show that the market risk neutral skewness can be calculated as

$$
S K E W_{m, t}(\tau)=\frac{e^{r \tau} W_{m, t}(\tau)-3 \mu_{i, t}(\tau) e^{r \tau} V_{m, t}(\tau)+2 \mu_{m, t}(\tau)^{3}}{\left[e^{r \tau} V_{m, t}(\tau)-\mu_{m, t}(\tau)^{2}\right]^{3 / 2}},
$$

where $\mu_{m, t}(\tau)=e^{r \tau}-1-e^{-r \tau} V_{m, t}(\tau) / 2-e^{-r \tau} W_{m, t}(\tau) / 6-e^{-r \tau} X_{m, t}(\tau) / 24$, and $r$ is the risk-free rate. The variance risk premium and signed jump variation risk premium's mean, median, minimum, maximum, and standard deviation are in percentage-square units. All statistics are monthly values. The sample period is January 1996 - December 2015 .

\begin{tabular}{|c|c|c|c|c|c|c|c|c|}
\hline & Mean & Median & Minimum & Maximum & StdDev & Skewness & Kurtosis & $\operatorname{AR}(1)$ \\
\hline$V R P_{m}^{b}$ & 13.83 & 10.56 & -5.44 & 98.83 & 15.31 & 2.03 & 8.85 & 0.80 \\
\hline$V R P_{m}^{g}$ & 0.61 & 1.11 & -17.97 & 76.27 & 8.79 & 3.94 & 31.42 & 0.49 \\
\hline$V R P_{m}$ & 13.20 & 9.87 & -17.34 & 79.20 & 17.05 & 1.18 & 4.56 & 0.39 \\
\hline$J R P_{m}$ & 14.44 & 8.96 & -2.25 & 147.05 & 18.23 & 3.78 & 22.09 & 0.78 \\
\hline$S K E W_{m}$ & -1.96 & -1.92 & -3.79 & -0.73 & 0.59 & -0.48 & 2.88 & 0.86 \\
\hline
\end{tabular}


Table 4: Univariate Sorts on Firm VRP

In Panel A, at the end of month $t$ we sort firms into quintiles based on their average bad VRP $\left(V R P^{b}\right)$ during month $t$, so that Quintile 1 contains the stocks with the lowest $V R P^{b}$ and Quintile 5 the highest. We then form value-weighted portfolios of these firms, holding the ranking constant for the next month. Subsequently, we compute cumulative returns during month $t+1$ for each quintile portfolio. We report the monthly average cumulative return in percentage of each portfolio. Similarly, in Panel B, C and D, we sort firms into quintiles based on their average good VRP $\left(V R P^{g}\right)$, total VRP $(V R P)$ and jump risk premium $(J R P)$, respectively. We also compute the Jensen alpha of each quintile portfolio with respect to the Fama-French five-factor model (Fama and French 2015) by running a time-series regression of the monthly portfolio returns on monthly $M K T, S M B, H M L, R M W$, and $C M A$. The t-statistics test the null hypothesis that the average monthly cumulative return of each respective portfolio equals zero, and they are computed using Newey and West (1987) standard errors to account for autocorrelation, and are reported in parentheses. Significant t-statistics at the $95 \%$ confidence level are boldfaced. VRP and $J R P$ are reported in monthly square percentage units.

\begin{tabular}{|c|c|c|c|c|c|c|c|c|c|c|c|c|}
\hline \multicolumn{7}{|c|}{ Panel A: Firm Bad VRP } & \multicolumn{6}{|c|}{ Panel B: Firm Good VRP } \\
\hline & \multicolumn{5}{|c|}{ Quintiles } & \multirow[b]{2}{*}{$5-1$} & \multicolumn{5}{|c|}{ Quintiles } & \multirow[b]{2}{*}{$5-1$} \\
\hline & 1 & 2 & 3 & 4 & 5 & & 1 & 2 & 3 & 4 & 5 & \\
\hline$V R P^{b}$ & -180.65 & 7.17 & 30.97 & 68.41 & 249.24 & & 121.15 & 39.29 & 27.99 & 25.42 & -38.71 & \\
\hline$V R P^{g}$ & 90.82 & 19.05 & 13.66 & 14.62 & 29.85 & & -62.18 & -7.18 & 8.29 & 31.34 & 197.72 & \\
\hline$V R P$ & -271.47 & -11.88 & 17.31 & 53.79 & 219.39 & & 183.33 & 46.47 & 19.70 & -5.92 & -236.43 & \\
\hline$J R P$ & -89.82 & 26.22 & 44.64 & 83.04 & 279.09 & & 58.98 & 32.11 & 36.29 & 56.76 & 159.01 & \\
\hline $\mathbb{E}[r]$ & $\begin{array}{c}0.06 \\
(0.15)\end{array}$ & $\begin{array}{c}0.63 \\
(\mathbf{2 . 3 1})\end{array}$ & $\begin{array}{c}1.02 \\
(\mathbf{3 . 0 2})\end{array}$ & $\begin{array}{c}1.28 \\
(\mathbf{2 . 7 6})\end{array}$ & $\begin{array}{c}1.14 \\
(1.90)\end{array}$ & $\begin{array}{c}1.08 \\
(\mathbf{2 . 7 3})\end{array}$ & $\begin{array}{c}0.17 \\
(0.44)\end{array}$ & $\begin{array}{c}0.60 \\
(\mathbf{2 . 1 3})\end{array}$ & $\begin{array}{c}1.03 \\
(\mathbf{3 . 3 3})\end{array}$ & $\begin{array}{c}1.00 \\
(\mathbf{2 . 4 2})\end{array}$ & $\begin{array}{c}0.64 \\
(1.02)\end{array}$ & $\begin{array}{c}0.48 \\
(1.35)\end{array}$ \\
\hline \multirow[t]{4}{*}{ alpha } & $\begin{array}{c}-0.76 \\
(-3.92)\end{array}$ & $\begin{array}{c}-0.16 \\
(-1.90)\end{array}$ & $\begin{array}{c}0.26 \\
(\mathbf{2 . 7 5})\end{array}$ & $\begin{array}{c}0.62 \\
(\mathbf{3 . 5 9})\end{array}$ & $\begin{array}{c}0.71 \\
(\mathbf{2 . 7 1})\end{array}$ & $\begin{array}{c}1.47 \\
(\mathbf{3 . 7 1})\end{array}$ & $\begin{array}{c}-0.38 \\
(-2.79)\end{array}$ & $\begin{array}{c}-0.25 \\
(-\mathbf{2 . 4 5})\end{array}$ & $\begin{array}{c}0.24 \\
(\mathbf{2 . 9 9})\end{array}$ & $\begin{array}{c}0.27 \\
(1.87)\end{array}$ & $\begin{array}{c}0.18 \\
(0.84)\end{array}$ & $\begin{array}{c}0.56 \\
(\mathbf{2 . 2 0})\end{array}$ \\
\hline & \multicolumn{6}{|c|}{ Panel C: Firm Total VRP } & \multicolumn{6}{|c|}{ Panel D: Firm JRP } \\
\hline & \multicolumn{5}{|c|}{ Quintiles } & & \multicolumn{5}{|c|}{ Quintiles } & \\
\hline & 1 & 2 & 3 & 4 & 5 & $5-1$ & 1 & 2 & 3 & 4 & 5 & $5-1$ \\
\hline$V R P^{b}$ & -159.55 & 9.99 & 29.53 & 62.82 & 232.36 & & -151.66 & 13.95 & 33.04 & 65.59 & 214.23 & \\
\hline$V R P^{g}$ & 168.33 & 26.27 & 9.34 & 0.17 & -36.10 & & 21.18 & 3.47 & 8.72 & 19.57 & 115.05 & \\
\hline$V R P$ & -327.88 & -16.27 & 20.19 & 62.65 & 268.45 & & -172.85 & 10.48 & 24.32 & 46.02 & 99.18 & \\
\hline$J R P$ & 8.78 & 36.26 & 38.86 & 62.99 & 196.26 & & -130.48 & 17.42 & 41.77 & 85.16 & 329.28 & \\
\hline $\mathbb{E}[r]$ & $\begin{array}{c}0.21 \\
(0.43)\end{array}$ & $\begin{array}{c}0.68 \\
(\mathbf{2 . 1 2})\end{array}$ & $\begin{array}{c}0.76 \\
(\mathbf{2 . 6 1})\end{array}$ & $\begin{array}{c}1.01 \\
(\mathbf{2 . 5 9})\end{array}$ & $\begin{array}{c}0.94 \\
(1.77)\end{array}$ & $\begin{array}{c}0.73 \\
(\mathbf{2 . 4 6})\end{array}$ & $\begin{array}{c}0.05 \\
(0.16)\end{array}$ & $\begin{array}{c}0.66 \\
(\mathbf{2 . 3 3})\end{array}$ & $\begin{array}{c}1.22 \\
(\mathbf{3 . 1 5})\end{array}$ & $\begin{array}{c}1.30 \\
(\mathbf{2 . 6 5})\end{array}$ & $\begin{array}{c}1.43 \\
(\mathbf{2 . 0 6})\end{array}$ & $\begin{array}{c}1.38 \\
(\mathbf{2 . 6 3})\end{array}$ \\
\hline alpha & $\begin{array}{c}-0.42 \\
(-\mathbf{2 . 2 5})\end{array}$ & $\begin{array}{c}-0.06 \\
(-0.52)\end{array}$ & $\begin{array}{l}-0.02 \\
(-0.19)\end{array}$ & $\begin{array}{c}0.26 \\
(1.72)\end{array}$ & $\begin{array}{c}0.42 \\
(1.94)\end{array}$ & $\begin{array}{c}0.84 \\
(\mathbf{2 . 5 1})\end{array}$ & $\begin{array}{c}-0.74 \\
(-5.27)\end{array}$ & $\begin{array}{c}-0.16 \\
(-\mathbf{2 . 2 9})\end{array}$ & $\begin{array}{c}0.44 \\
(\mathbf{3 . 3 7})\end{array}$ & $\begin{array}{c}0.75 \\
(\mathbf{3 . 8 3})\end{array}$ & $\begin{array}{c}1.05 \\
(\mathbf{3 . 8 0})\end{array}$ & $\begin{array}{c}1.78 \\
(\mathbf{5 . 0 9})\end{array}$ \\
\hline
\end{tabular}



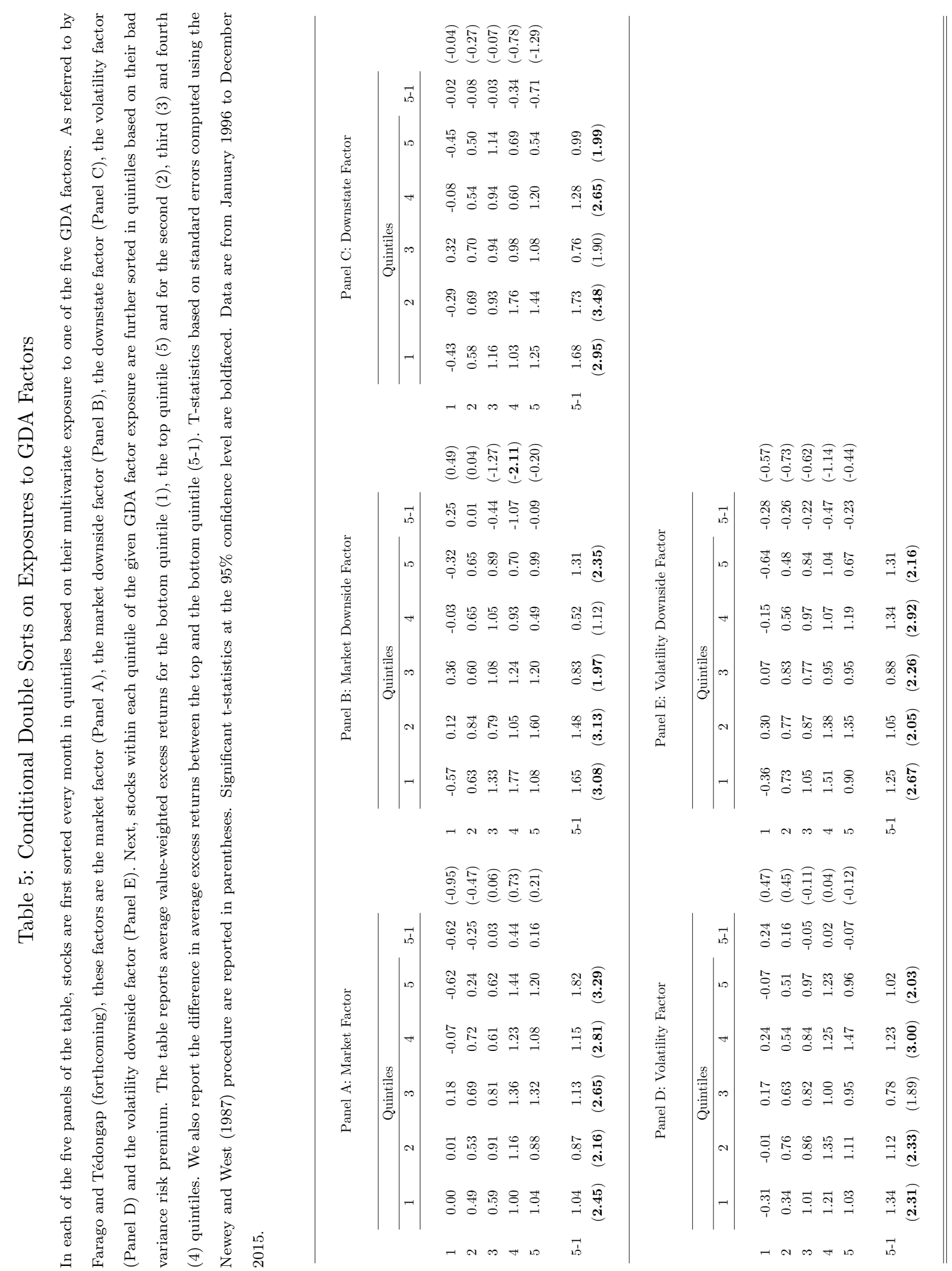


\section{Table 6: Conditional Double Sorts on Exposures to Other Market Factors}

Stocks are sorted every month in quintiles based on their exposure to market bad VRP in Panel A, and their exposure to the market risk neutral skewness in Panel B. Then, stocks within each quintile of exposure to these factors are further sorted in quintiles based on their bad VRP. Firm exposures to market bad VRP are estimated following the three-factor model implied by the general equilibrium setting of Bollerslev et al. (2009), i.e, with market excess returns, conditional market variance, and volatility of volatility, and where we replace volatility of volatility by the bad and good VRP. Firm exposures to market risk-neutral skewness are estimated following the model of Chang et al. (2013). The table reports average value-weighted excess returns for the bottom quintile (1), the top quintile (5) and for the second (2), third (3) and fourth (4) quintile. We also report the difference in average excess returns between the top and the bottom quintile (5-1). T-statistics are computed using Newey and West (1987) standard errors, and are reported in parentheses. Significant t-statistics at the $95 \%$ confidence level are boldfaced. Data are from January 1996 to December 2015.

\begin{tabular}{|c|c|c|c|c|c|c|c|c|c|c|c|c|c|c|}
\hline \multicolumn{7}{|c|}{ Panel A: Market Bad VRP } & \multicolumn{8}{|c|}{ Panel B: Market Risk Neutral Skewness } \\
\hline & \multicolumn{5}{|c|}{ Quintiles } & \multirow[b]{2}{*}{$5-1$} & & \multicolumn{5}{|c|}{ Quintiles } & \multirow[b]{2}{*}{$5-1$} & \\
\hline & 1 & 2 & 3 & 4 & 5 & & & 1 & 2 & 3 & 4 & 5 & & \\
\hline 1 & -0.64 & 0.31 & 0.16 & -0.09 & -0.34 & 0.30 & $(0.73)$ & -0.10 & 0.27 & 0.06 & 0.07 & -0.84 & -0.74 & $(-1.30)$ \\
\hline 2 & 0.34 & 0.79 & 0.63 & 0.62 & 0.57 & 0.23 & $(0.65)$ & 0.80 & 0.56 & 0.50 & 0.81 & 0.90 & 0.10 & $(0.28)$ \\
\hline 3 & 0.94 & 0.78 & 0.92 & 0.91 & 1.36 & 0.42 & (1.03) & 0.96 & 1.18 & 0.62 & 0.87 & 1.22 & 0.26 & $(0.71)$ \\
\hline 4 & 1.05 & 1.28 & 1.15 & 1.28 & 1.12 & 0.07 & $(0.14)$ & 0.76 & 1.03 & 1.14 & 1.21 & 1.32 & 0.56 & $(1.31)$ \\
\hline 5 & 0.44 & 1.74 & 1.44 & 1.37 & 0.79 & 0.34 & $(0.62)$ & 1.13 & 1.26 & 1.24 & 1.42 & 0.96 & -0.17 & $(-0.29)$ \\
\hline $5-1$ & $\begin{array}{c}1.08 \\
(\mathbf{2 . 3 5})\end{array}$ & $\begin{array}{c}1.43 \\
(\mathbf{3 . 1 8})\end{array}$ & $\begin{array}{c}1.28 \\
(\mathbf{2 . 9 7})\end{array}$ & $\begin{array}{c}1.46 \\
(\mathbf{3 . 5 7})\end{array}$ & $\begin{array}{c}1.12 \\
(\mathbf{2 . 1 0})\end{array}$ & & & $\begin{array}{c}1.23 \\
(\mathbf{2 . 2 9})\end{array}$ & $\begin{array}{c}0.99 \\
(\mathbf{2 . 3 1})\end{array}$ & $\begin{array}{c}1.18 \\
(\mathbf{2 . 7 0})\end{array}$ & $\begin{array}{c}1.35 \\
(\mathbf{2 . 7 6})\end{array}$ & $\begin{array}{c}1.80 \\
(\mathbf{3 . 3 2})\end{array}$ & & \\
\hline
\end{tabular}




\section{Table 7: Conditional Double Sorts on Other Firm Characteristics}

In each of the four panels of the table, stocks are sorted every month in quintiles based on four different firm characteristics: illiquidity, idiosyncratic volatility, risk neutral skewness, and relative signed jump variation, respectively. Then, stocks within each quintile are further sorted in quintiles based on their bad variance risk premium. Illiquidity is measured as in Amihud (2002). Idiosyncratic volatility is estimated following Ang et al. (2006b). Risk neutral skewness is estimated following Bakshi et al. (2003). Relative signed jump variation is estimated following Bollerslev et al. (2017). T-statistics are computed using Newey and West (1987) standard errors, and are reported in parentheses. Significant t-statistics at the $95 \%$ confidence level are boldfaced.

Panel A: Illiquidity

\begin{tabular}{llclll}
\hline \multicolumn{7}{c}{ Quintiles } \\
\cline { 1 - 4 } & 2 & 3 & 4 & 5 & $5-1$
\end{tabular}

$\begin{array}{cccccccc}1 & 0.24 & 0.08 & -0.28 & -0.61 & -1.10 & -1.35 & (-\mathbf{3 . 1 0}) \\ 2 & 0.77 & 0.73 & 0.75 & 0.63 & 0.40 & -0.37 & (-0.99) \\ 3 & 0.73 & 1.02 & 1.11 & 0.96 & 0.95 & 0.22 & (0.67) \\ 4 & 1.06 & 1.13 & 1.25 & 1.09 & 1.29 & 0.23 & (0.58) \\ 5 & 1.25 & 1.42 & 0.79 & 1.70 & 0.43 & -0.82 & (-1.90) \\ & & & & & & & \\ 5-1 & 1.01 & 1.34 & 1.07 & 2.31 & 1.53 & & \\ & (\mathbf{2 . 8 5}) & (\mathbf{4 . 2 1}) & (\mathbf{3 . 4 3}) & (\mathbf{6 . 2 1}) & (\mathbf{3 . 9 4}) & & \end{array}$

Panel B: Idiosyncratic Volatility

\begin{tabular}{|c|c|c|c|c|c|c|}
\hline \multicolumn{5}{|c|}{ Quintiles } & \multirow[b]{2}{*}{$5-1$} & \\
\hline 1 & 2 & 3 & 4 & 5 & & \\
\hline 0.53 & 0.09 & -0.23 & -0.61 & -1.33 & -1.86 & $(-2.73)$ \\
\hline 0.79 & 0.59 & 0.41 & 0.14 & 0.17 & -0.62 & $(-1.25)$ \\
\hline 0.85 & 0.91 & 0.91 & 1.04 & 0.60 & -0.25 & $(-0.52)$ \\
\hline 0.97 & 1.20 & 1.09 & 1.41 & 0.70 & -0.27 & $(-0.44)$ \\
\hline 1.22 & 1.54 & 1.31 & 0.91 & 0.47 & -0.75 & $(-1.16)$ \\
\hline $\begin{array}{c}0.69 \\
(\mathbf{2 . 4 6})\end{array}$ & $\begin{array}{c}1.45 \\
(4.14)\end{array}$ & $\begin{array}{c}1.54 \\
(\mathbf{3 . 4 5})\end{array}$ & $\begin{array}{c}1.52 \\
(\mathbf{2 . 9 7})\end{array}$ & $\begin{array}{c}1.80 \\
(\mathbf{2 . 8 3})\end{array}$ & & \\
\hline
\end{tabular}

Panel C: Risk Neutral Skewness

\begin{tabular}{llclll}
\hline \multicolumn{5}{c}{ Quintiles } \\
\cline { 1 - 4 } 1 & 2 & 3 & 4 & 5 & $5-1$ \\
\hline
\end{tabular}

$\begin{array}{llllllll}1 & 0.31 & 0.30 & -0.08 & -0.57 & -0.37 & -0.67 & (\mathbf{- 1 . 9 6})\end{array}$

$\begin{array}{llllllll}2 & 0.62 & 0.76 & 0.52 & 0.72 & 0.37 & -0.25 & (-0.86)\end{array}$

$\begin{array}{llllllll}3 & 0.75 & 1.32 & 1.33 & 1.25 & 1.17 & 0.42 & (1.39)\end{array}$

$\begin{array}{llllllll}4 & 1.55 & 1.23 & 1.43 & 1.11 & 1.19 & -0.35 & (-0.82)\end{array}$

$\begin{array}{llllllll}5 & 1.08 & 1.38 & 1.30 & 1.18 & 1.35 & 0.28 & (0.55)\end{array}$

$\begin{array}{llllll}5-1 & 0.77 & 1.08 & 1.38 & 1.75 & 1.72\end{array}$

$\begin{array}{lllll}(1.59) & (\mathbf{1 . 9 8}) & (\mathbf{2 . 7 2}) & (\mathbf{3 . 3 2}) & (\mathbf{3 . 3 3})\end{array}$
Panel D: Relative Signed Jump Variation

\begin{tabular}{|c|c|c|c|c|c|c|}
\hline \multicolumn{5}{|c|}{ Quintiles } & \multirow[b]{2}{*}{$5-1$} & \\
\hline 1 & 2 & 3 & 4 & 5 & & \\
\hline-0.87 & 0.07 & -0.07 & 0.06 & 0.41 & 1.28 & $(2.95)$ \\
\hline 0.60 & 0.66 & 0.74 & 0.60 & 0.58 & -0.02 & $(-0.06)$ \\
\hline 1.27 & 1.12 & 1.25 & 0.94 & 0.82 & -0.45 & $(-1.31)$ \\
\hline 1.49 & 1.31 & 1.20 & 1.08 & 1.36 & -0.12 & $(-0.24)$ \\
\hline 0.87 & 0.85 & 1.08 & 1.15 & 1.75 & 0.87 & $(1.41)$ \\
\hline 1.74 & 0.78 & 1.14 & 1.09 & 1.34 & & \\
\hline (3.33) & $(1.56)$ & $(2.21)$ & $(2.43)$ & $(\mathbf{2 . 6 5})$ & & \\
\hline
\end{tabular}




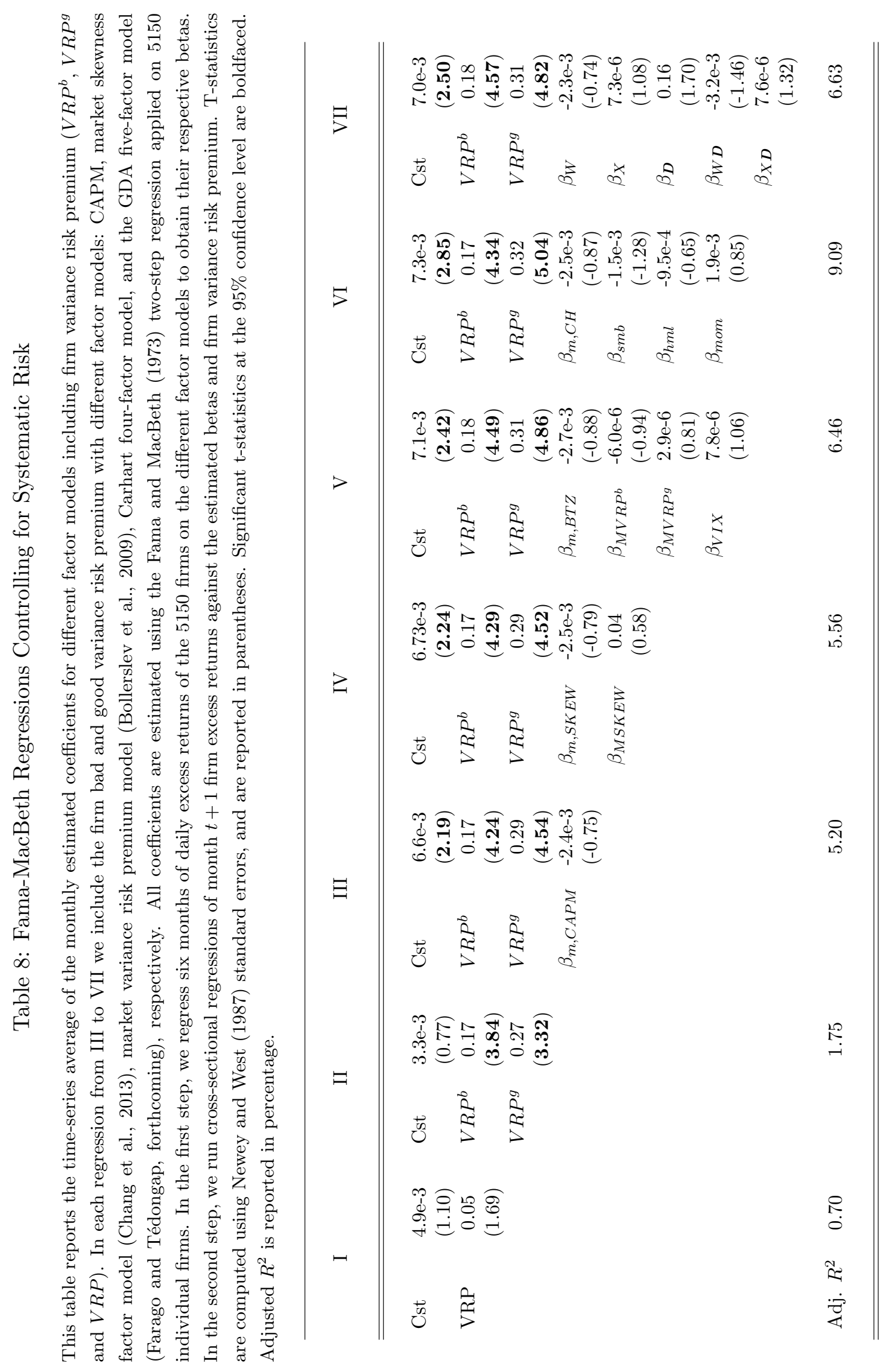




\section{Table 9: Fama-MacBeth Regressions Controlling for Other Firm Characteristics}

This table reports the time-series average of the monthly estimated coefficients for different factor models including firm variance risk premium $\left(V R P^{b}, V R P^{g}\right.$ and $\left.V R P\right)$. In regression VIII we include the firm bad and good variance risk premium with the relative signed jump variation $(R S J)$ from Bollerslev et al. (2017). In regression IX we include the firm bad and good variance risk premium with all the firm characteristics: $R S J$, idiosyncratic volatility $(I V O L)$ computed as in Ang et al. (2006b), past 1-month cumulative excess return (P01M), past 12-month cumulative excess return $(\mathrm{P} 12 \mathrm{M})$, size, book-to-market $(\mathrm{B} / \mathrm{M})$, illiquidity $(I L L I Q)$, risk-neutral skewness $(S K E W)$, the good and bad realized semi-variances $\left(R V^{b}\right.$ and $\left.R V^{g}\right)$, and firm risk neutral skewness. All coefficients are estimated using the Fama and MacBeth (1973) two-step regression applied on 5150 individual firms. We run cross-sectional regressions of month $t+1$ firm excess returns against firm characteristics and firm variance risk premium. T-statistics are computed using Newey and West (1987) standard errors, and are reported in parentheses. Significant t-statistics at the $95 \%$ confidence level are boldfaced. Adjusted $R^{2}$ is reported in percentage.

\begin{tabular}{|c|c|c|c|c|c|c|c|}
\hline \multicolumn{2}{|c|}{ I } & \multicolumn{2}{|c|}{ II } & \multicolumn{2}{|c|}{ VIII } & \multicolumn{2}{|c|}{ IX } \\
\hline Cst & $\begin{array}{l}4.9 \mathrm{e}-3 \\
(1.10)\end{array}$ & Cst & $\begin{array}{l}3.3 \mathrm{e}-3 \\
(0.77)\end{array}$ & Cst & $\begin{array}{c}3.4 \mathrm{e}-3 \\
(0.80)\end{array}$ & Cst & $\begin{array}{c}3.2 \mathrm{e}-3 \\
(0.18)\end{array}$ \\
\hline \multirow[t]{12}{*}{ VRP } & $\begin{array}{c}0.05 \\
(1.69)\end{array}$ & $V R P^{b}$ & $\begin{array}{c}0.17 \\
(\mathbf{3 . 8 4})\end{array}$ & $V R P^{b}$ & $\begin{array}{c}0.17 \\
(\mathbf{3 . 8 1})\end{array}$ & $V R P^{b}$ & $\begin{array}{c}0.32 \\
(\mathbf{4 . 7 7})\end{array}$ \\
\hline & & $V R P^{g}$ & $\begin{array}{c}0.27 \\
(\mathbf{3 . 3 2})\end{array}$ & $V R P^{g}$ & $\begin{array}{c}0.27 \\
(\mathbf{3 . 3 4})\end{array}$ & $V R P^{g}$ & $\begin{array}{c}0.61 \\
(\mathbf{5 . 2 1})\end{array}$ \\
\hline & & & & $R S J$ & $\begin{array}{c}-1.5 \mathrm{e}-3 \\
(-0.40)\end{array}$ & $R S J$ & $\begin{array}{c}5.2 \mathrm{e}-3 \\
(1.73)\end{array}$ \\
\hline & & & & & & $I V O L$ & $\begin{array}{l}-0.12 \\
(-1.41)\end{array}$ \\
\hline & & & & & & $\mathrm{P} 01 \mathrm{M}$ & $\begin{array}{r}-0.02 \\
-\mathbf{2 . 4 8}\end{array}$ \\
\hline & & & & & & $\mathrm{P} 12 \mathrm{M}$ & $\begin{array}{c}3.9 \mathrm{e}-3 \\
(1.41)\end{array}$ \\
\hline & & & & & & Size & $\begin{array}{c}5.0 \mathrm{e}-5 \\
(0.07)\end{array}$ \\
\hline & & & & & & $\mathrm{B} / \mathrm{M}$ & $\begin{array}{c}0.02 \\
(\mathbf{3 . 9 0})\end{array}$ \\
\hline & & & & & & ILLIQ & $\begin{array}{l}-0.35 \\
(-1.22)\end{array}$ \\
\hline & & & & & & $R V^{b}$ & $\begin{array}{c}-0.28 \\
(-\mathbf{2 . 3 8}\end{array}$ \\
\hline & & & & & & $R V^{g}$ & $\begin{array}{c}-0.06 \\
(-0.50)\end{array}$ \\
\hline & & & & & & $S K E W$ & $\begin{array}{l}4.5 \mathrm{e}-3 \\
(\mathbf{3 . 3 3})\end{array}$ \\
\hline Adj. $R^{2}$ & 0.70 & Adj. $R^{2}$ & 1.75 & Adj. $R^{2}$ & 2.68 & Adj. $R^{2}$ & 10.54 \\
\hline
\end{tabular}

